E19-2014-39

O. V. Belov ${ }^{1, *}$, E. A. Krasavin ${ }^{1}$, M. S. Lyashko ${ }^{1}$, M. Batmunkh ${ }^{1,2}$, N. H. Sweilam ${ }^{3}$

\title{
A QUANTITATIVE MODEL OF THE MAJOR PATHWAYS FOR RADIATION-INDUCED DNA DOUBLE-STRAND BREAK REPAIR
}

Submitted to «Journal of Theoretical Biology»

\footnotetext{
${ }^{1}$ Laboratory of Radiation Biology, JINR, Dubna

${ }^{2}$ School of Physics and Electronics, National University of Mongolia, Ulaanbaatar

${ }^{3}$ Mathematics Department, Faculty of Science, Cairo University, Giza, Egypt * Corresponding author: Dr. O. V. Belov. Laboratory of Radiation Biology, JINR, 6 Joliot-Curie St., 141980 Dubna, Moscow Region, Russia.

Telephone: +74962162847. E-mail: dem@jinr.ru
} 
Белов О. В. и др.

Математическая модель репарации

радиационно-индуцированных двунитевых разрывов ДНК

Разработана математическая модель, описывающая основные пути репарации двунитевых разрывов (ДР) ДНК в клетках млекопитающих и человека. Предложенный расчетный подход отражает возможные молекулярные механизмы, лежащие в основе восстановления ДР ДНК путем негомологичного воссоединения концов (NHEJ), гомологичной рекомбинации (HR) и однонитевого отжига по прямым повторам (SSA). Модель корректно воспроизводит временные характеристики индукции фокусов, специфичных для ключевых этапов воссоединения ДР при действии ионизирующих излучений в широком диапазоне значений линейной передачи энергии $(0,2-236$ кэВ/мкм). В работе найден набор параметров, удовлетворяющий экспериментально наблюдаемым закономерностям восстановления повреждений после воздействия рассмотренных видов излучения. Учет всех трех репарационных механизмов позволяет описать их возможное взаимодействие в ходе ответа клетки на облучение. Показано, что предложенная математическая модель может быть использована для описания кинетики уровня фокусов $\gamma$-H2AX в различных видах клеток, в том числе содержащих дефекты в одной из трех систем репарации.

Работа выполнена в Лаборатории радиационной биологии ОИЯИ.

Препринт Объединенного института ядерных исследований. Дубна, 2014

Belov O. V. et al.

E19-2014-39

A Quantitative Model of the Major Pathways for Radiation-Induced DNA

Double-Strand Break Repair

We have developed a model approach to simulate the major pathways of DNA doublestrand break (DSB) repair in mammalian and human cells. The proposed model shows a possible mechanistic explanation of the basic regularities of DSB processing through the nonhomologous end-joining (NHEJ), homologous recombination (HR), and single-strand annealing (SSA). It reconstructs the time-courses of radiation-induced foci specific to particular repair processes including the major intermediate stages. The model is validated for ionizing radiations of a wide range of linear energy transfer $(0.2-236 \mathrm{keV} / \mu \mathrm{m})$ including a relatively broad spectrum of heavy ions. The appropriate set of reaction rate constants was suggested to satisfy the kinetics of DSB rejoining for the considered types of exposure. The simultaneous assessment of three repair pathways allows one to describe their possible biological relations in response to radiation. With the help of the proposed approach, we reproduce several experimental data sets on $\gamma-\mathrm{H} 2 \mathrm{AX}$ foci remaining in different types of cells including those defective in NHEJ, HR, or SSA functions.

The investigation has been performed at the Laboratory of Radiation Biology, JINR.

Preprint of the Joint Institute for Nuclear Research. Dubna, 2014 


\section{INTRODUCTION}

Along with experimental research, the theoretical study of DNA repair pathways has become increasingly important for complex understanding of their biological endpoints. One of the widely discussed problems in this field is the simulation of DNA double-strand break (DSB) rejoining in eukaryotic cells. As is known, this type of DNA lesions is one of the most deleterious, since is capable of stimulating cell cycle arrest and cell death with high probability (Negritto 2010). If not repaired correctly, DSBs can lead to induction of structural gene mutations, chromosome aberrations, and possible initiation of the malignant cell transformation, which can be a causal event of carcinogenesis.

Among the environmental factors inducing DSBs, the exposure to ionizing radiation is of great interest. In this regard, an important problem is represented by comparative studying of DSB repair under the action of radiations with different linear energy transfer (LET). In this case mathematical models allow summarizing a large quantity of experimental data and help to understand the repair stages hardly accessible to measurements.

Until now, most of the experimental data on DSB repair regularities has been obtained for sparsely ionizing radiations represented mainly by $\gamma$ - and X-rays, which have low LET. However, the amount of knowledge on high-LET radiations also increases. In this regard, there is a specific task of studying DSB repair after exposure to accelerated heavy ions (also called high-energy and high-Z (HZE) particles). DNA lesions produced by this type of radiation may possess a high complexity and follow to a more complicated manner of repair. When DSB is accompanied by two or more other lesions formed within one or two helical turns of the DNA, it is usually considered as a clustered DSB (Gulston et al. 2002). Along with the frank radiation-induced breaks, DSBs can be also created during failed repair of other DNA lesions or due to possible collapse of a replication fork when it encounters a single-strand break (SSB) (Wallace 1998; Saleh-Gohari et al. 2005).

Higher eukaryotes possess three principal repair pathways to recover DSBs, namely nonhomologous end-joining (NHEJ), homologous recombination (HR), and single-strand annealing (SSA) (Heyer et al. 2010). NHEJ and SSA are usually referred to as the error-prone repair while HR is accepted to be error-free (Frankenberg-Schwager et al. 2009). These systems have different specificity 
in relation to the cell cycle. In mammalian and human cells, NHEJ represents the major DSB repair process, capable to eliminate lesions over all the cell cycle phases (Mahaney et al. 2009). It does not require a homologous sequence, and therefore, occurs more frequently than HR. In contrast to NHEJ, it is accepted that $\mathrm{HR}$ is restricted to the late $\mathrm{S}$ and $\mathrm{G}_{2}$ phases due to several factors including the presence of a sister chromatid, the transcription of HR genes, and CDK-mediated phosphorylation of HR proteins (Moynahan and Jasin 2010). The SSA pathway is a homology-directed DNA repair, which promotes recombination between tandemly repeated DNA sequences and involves the reannealing of RPA-covered single-stranded DNA (ssDNA). Whereas SSA is initiated similarly to $\mathrm{HR}$, it requires a different repertoire of proteins and, therefore, represents an independent repair system. In the case of clustered DSB, several repair pathways may sequentially attempt to recover it (Shibata et al. 2011). In the context of theoretical studies, it requires the development of new simulation approaches considering kinetics of DSB rejoining via multiply mechanisms.

The majority of the existing papers on simulation of DSB rejoining in eukaryotes focus mainly on the lesions induced by sparsely ionizing radiations possessing low-LET and they do not consider possible interactions between different repair pathways (Cucinotta et al. 2008; Bastin et al. 1992; Goodhead 1985; Kiefer 1988; Cucinotta 2000; Taleei et al. 2012; Taleei et al. 2013). Moreover, until now the published works have not presented rate constants for the particular repair processes in case of simultaneous functioning of several repair systems. Compared to these findings, our study is aimed at the development of a mathematical model that would be able to describe simultaneously three major DSB repair pathways in mammalian and human cells after exposure to both low- and high-LET radiations.

The suggested model takes into account most of the recently identified proteins involved in the NHEJ, HR, and SSA pathways. Our calculations are validated by comparing the kinetics of different repair stages to experimentally observed time-courses of corresponding radiation-induced fluorescent foci. The results on final DSB rejoining are verified against the data on $\gamma-\mathrm{H} 2 \mathrm{AX}$ foci detection after irradiation (Huang and Darzynkiewicz 2006).

\section{MATHEMATICAL MODEL}

The proposed mathematical model consists of four main parts. The first one represents a possible approach to estimate the initial yield of radiation-induced DSBs. The other parts are referred to quantitative models of NHEJ, HR, and SSA repair systems, respectively. In our analysis we use the mass-action chemical kinetics approach to simulate the processing of DNA lesions by enzymes specific for each pathway. 
2.1. Calculation of DSB Induction. Since the total yield $\left(N_{0}\right)$ of DSBs is linearly related to the dose both for low- and high-LET radiations, the rate of their induction can be calculated by

$$
\frac{d N_{0}}{d t}=\alpha(L) \frac{d D}{d t} N_{i r}-V_{\mathrm{NHEJ}}-V_{\mathrm{HR}}-V_{\mathrm{SSA}}
$$

similarly as it is done in (Cucinotta et al. 2008; Taleei et al. 2012; Taleei and Nikjoo 2013). In Eq. (1), $D$ is the dose of ionizing radiation $(\mathrm{Gy}) ; \alpha(L)$ is the slop coefficient of linear dose dependence which describes DSB induction per unit of dose $\left(\mathrm{Gy}^{-1}\right.$ per cell) and depends on LET; $V_{\mathrm{NHEJ}}, V_{\mathrm{HR}}$, and $V_{\mathrm{SSA}}$ are the terms characterizing elimination of DSBs by the NHEJ, HR, and SSA repair pathways respectively. The exact views of these terms are given in Eqs. A.1 of Appendix A in concordance with the initial stages of corresponding repair systems. In our calculations, we assume that both $\mathrm{Ku}$ - and $\mathrm{MRN}$-initiated pathways compete for DNA lesions and the choice of the pathway in general, as it is suggested in (Shibata et al. 2011), is regulated by the speed of different repair mechanisms. In Eq. (1), we have also introduced the share of irreparable DSBs $\left(N_{i r}\right)$ which results in $\gamma$-H2AX foci remained in the cell $24 \mathrm{~h}$ and later after irradiation.

2.2. Quantitative Model of the NHEJ Pathway. Recent experimental data allows the identification of major biochemical processes referred to NHEJ in mammalian and human cells. In our model, we assume the following molecular mechanism to be realized in the course of this repair (Fig. 1). First, Ku complex binds to an occurred DSB. Ku heterodimer is composed of proteins $\mathrm{Ku} 70$ and Ku86 (also known as Ku80) which are contained in cells in large numbers (about 400,000 molecules per cell), and it possesses a high affinity for DNA ends (Neal and Meek 2011; Blier et al.1993). This complex binds to a DSB forming an asymmetric ring which can surround break ends in a sequence-independent manner by binding to the DNA backbone but not with the DNA bases (Walker et al.2001). Ku getting bound to a DSB initiates NHEJ. This stage can be represented by the following kinetic scheme:

$$
[\mathrm{DSB}]+[\mathrm{Ku}] \underset{K_{-1}}{\stackrel{K_{1}}{\leftrightarrows}}[\mathrm{DSB} \cdot \mathrm{Ku}]
$$

where quantities in brackets denote time-dependent intracellular concentrations of repair complexes; $K$ values with an appropriate subscript used represent the dimensional reaction rate-constants. Here [DSB] is the number of DSBs that undergo binding by $\mathrm{Ku}$; $[\mathrm{DSB} \cdot \mathrm{Ku}]$ is the level of resulting intermediate complex.

At the next stage, $\mathrm{Ku}$ recruits the DNA-dependent protein kinase catalytic subunit (DNA-PKcs) and Artemis to a DSB site. The binding of these specific protein factors limits DNA strand degradation, which can lead to the loss of genetic information (Hefferin and Tomkinson 2005). This stage distinguishes NHEJ from recombinational repair pathways, where degradation of 5' strand 


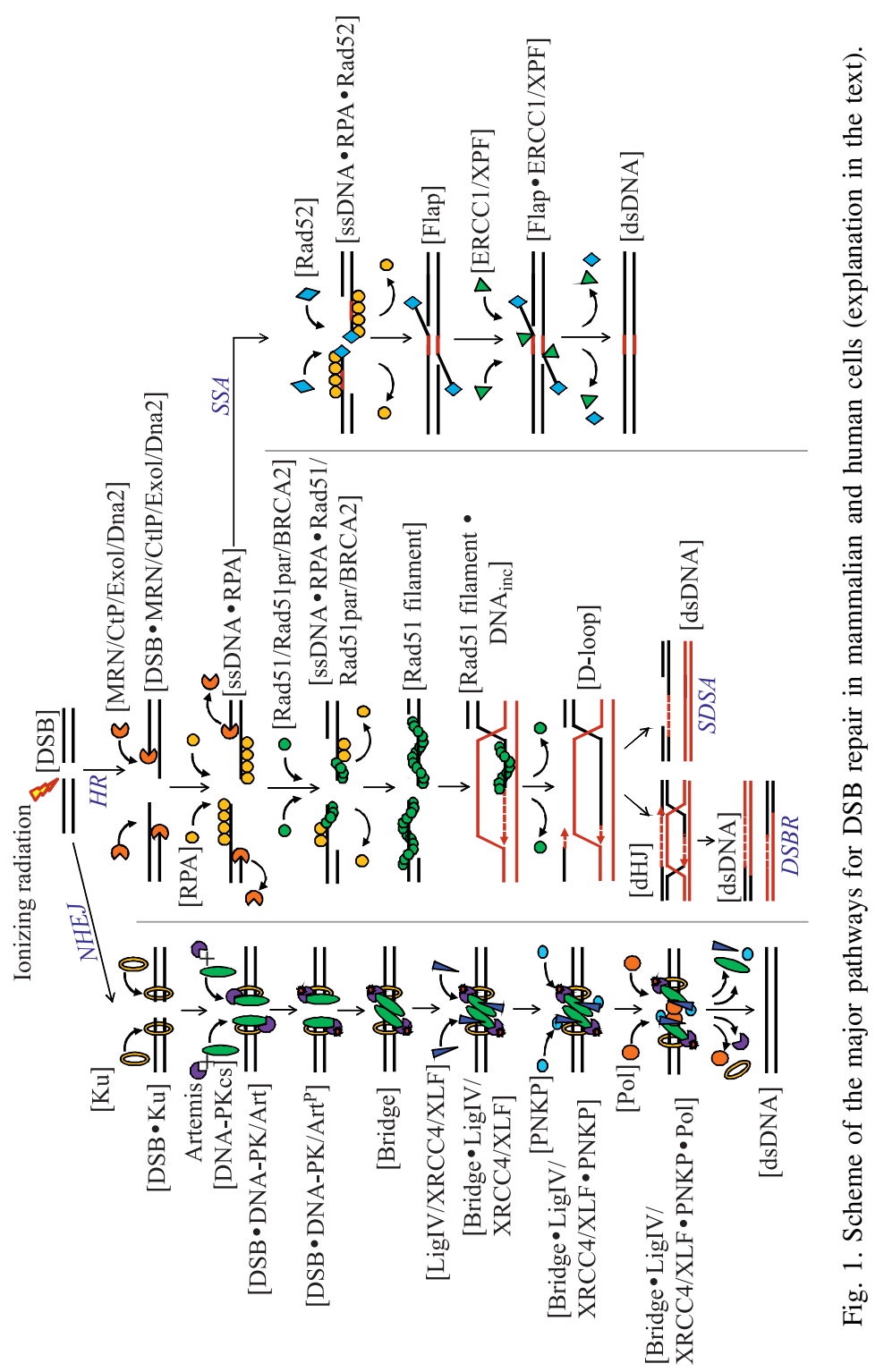


leads to appearance of a single-stranded sequence used to search for homology. DNA-PKcs is one of the largest kinases identified to date, and it is the only kinase that is absolutely dependent on DNA binding for activity (Neal and Meek 2011). When DNA-PKcs is recruited to the DSB site, Ku complex moves inward allowing DNA-PKcs to contact with a shot region ( $\sim 10$ base pairs) at the DNA termini (Yoo and Dynan 1999). It is known that DNA-PKcs can also bind to double-stranded DNA (dsDNA) ends and be activated under low salt conditions, however $\mathrm{Ku}$ complex stimulates the kinase activity significantly (Yaneva et al. 1997; Hammarsten and Chu 1998). Artemis is another one-end processing factor necessary for efficient NHEJ (Moshous et al. 2000; Moshous et al. 2001), however its exact role in this repair pathway remains not fully understood. It was initially suggested that Artemis possesses a 5' exonuclease activity specific for ssDNA (Ma et al. 2002). Later, the purification of Artemis showed that this activity can be separated from this protein (Pawelczak and Turchi 2010). Although the 5' exonuclease activity is not an intrinsic property of Artemis, recent studies have indicated the relevance of this complex for NHEJ. The observation that Artemis-mutant mice are also radiosensitive (Rooney et al. 2003) suggests its additional role in the repair pathway. Resent findings presume that $5^{\prime}$ and 3 ' endonuclease activities of Artemis may be responsible for removing ssDNA overhangs containing damaged DNA bases during end processing (Kurosawa and Adachi 2010; Neal and Meek 2011). Additionally, Artemis is considered to be the nuclease required for opening the DNA hairpin ends produced during coding joint formation in $\mathrm{V}(\mathrm{D}) \mathrm{J}$ (variable (division) joining) recombination (Ma et al. 2002). Due to the diversity of experimental findings, we consider Artemis as a subsidiary protein and do not assign a special variable for its level:

$$
[\mathrm{DSB} \cdot \mathrm{Ku}]+[\mathrm{DNA}-\mathrm{PKCs}] \underset{K_{-2}}{\stackrel{K_{2}}{\leftrightarrows}}[\mathrm{DSB} \cdot \mathrm{DNA}-\mathrm{PK} / \mathrm{Art}] .
$$

In this kinetic equation [DNA-PK] denotes a complex of Ku and DNA-PKcs. Art indicates that the mentioned intermediate complex is formed in the presence of Artemis.

DNA-PK is able to phosphorylate a number of proteins involved in NHEJ. In particular, $\mathrm{Ku} 70$ and $\mathrm{Ku} 86$, Artemis, the $\mathrm{X}$-ray cross complementing protein 4 (XRCC4), the XRCC4-like factor (XLF), and DNA ligase IV (LigIV) are the phosphorylation substrates for DNA-PK (Neal and Meek 2011). It was proven recently, however, that among all mentioned targets for DNA-PK-mediated phosphorylation, only the autophosphorylation of DNA-PKcs has a biological significance (Chen et al. 2005; Meek et al. 2007). Therefore, the corresponding repair stage can be denoted as the following irreversible process:

$$
[\mathrm{DSB} \cdot \mathrm{DNA}-\mathrm{PK} / \mathrm{Art}] \stackrel{K_{3}}{\longrightarrow}\left[\mathrm{DSB} \cdot \mathrm{DNA}-\mathrm{PK} / \mathrm{Art}^{\mathrm{P}}\right],
$$

where P superscript defines the phosphorylated DNA-PK. 
In our model, the end bridging process is described as a junction of two $\left[\mathrm{DSB}_{\mathrm{NHEJ}} \cdot\left[\mathrm{DNA}-\mathrm{PK} / \mathrm{Art}^{\mathrm{P}}\right]\right.$ constructs formed at the previous repair stage:

$$
\left[\mathrm{DSB} \cdot \mathrm{DNA}-\mathrm{PK} / \mathrm{Art}^{\mathrm{P}}\right]+\left[\mathrm{DSB} \cdot \mathrm{DNA}-\mathrm{PK} / \mathrm{Art}^{\mathrm{P}}\right] \underset{K_{-4}}{\stackrel{K_{4}}{\leftrightarrows}}[\text { Bridge }]
$$

It is assumed there that the [Bridge] intermediate complex includes a DSB itself, the molecules of DNA-PK and Artemis. It is believed that the end bridging is mediated by protein-protein interactions between the DNA-PKcs molecules located at the DSB site (Hefferin and Tomkinson 2005).

The assembling of DNA-PK also promotes the recruitment of LigIV and its associated factor, XRCC4. The majority of studies indicate a primary role of LigIV in sealing DNA ends in mammalian and human cells (Frank et al. 1998; O'Driscoll et al. 2001). XRCC4 itself does not demonstrate any known enzymatic activity; but its binding increases the stability of LigIV (Bryans et al. 1999) and the activity of this enzyme at the adenylation stage (Grawunder et al. 1997). The recruitment of XRCC4 occurs through its interaction with a special region, separating the two C-terminal BRCA1 carboxyl terminus domains of LigIV (Grawunder et al. 1998). Recent findings suggest that the LigIV/XRCC4 complex is able to ligate broken DNA strands in a specific manner. It can seal one broken DNA strand of a DSB, even if the other strand is not ligatable (Ma Y. et al. 2004). It may indicate that end processing and ligation can occur independently and, therefore, simultaneously. It was reviewed that additional factor involved in NHEJ-dependent ligation is XLF (Buck D et al. 2006). Although the exact role of this factor is not clear, several important activities of XLF are indicated. Notably, it stimulates the activity of the LigIV/XRCC4 complex toward mismatched or non-cohesive DNA ends and may play a role in facilitating DNA end alignment (Andres et al. 2007). Following the above mentioned data, the simulation of the ligation stage is performed with the consideration to the most biologically significant features of this process. LigIV, XRCC4, and XLF are assumed to be recruited to a DSB site simultaneously. Since the exact order of the factors binding is still an open question, the substages of this process are omitted:

$$
[\text { Bridge }]+[\operatorname{LigIV} / \text { XRCC4 } / \text { XLF }] \underset{K_{-5}}{\stackrel{K_{5}}{\leftrightarrows}}[\text { Bridge } \cdot \operatorname{LigIV} / \text { XRCC4/XLF }]
$$

Further processing of a DSB implies recruitment of polynucleotide kinase phosphatase (PNKP) to a break site. It was revealed that in mammalian and human cells PNKP, which possesses both 5' kinase and 3' phosphatase activities (Karimi-Busheri et al 1999), interacts with the XRCC4 subunit of LigIV/XRCC4 complex, suggesting a possible molecular mechanism for the participation of PNKP in NHEJ (Mani et al. 2010). Additional findings, indicating an increase of radiosensitivity in cells with depleted levels of PNKP (Koch et al. 2004), made us 
to consider the recruitment of this factor as a biologically significant mechanism. Therefore this stage is also introduced in the model and described by

$$
\begin{aligned}
{[\text { Bridge } \cdot \operatorname{LigIV} / \mathrm{XRCC} 4 / \mathrm{XLF}]+[\mathrm{PNKP}] \underset{K_{-6}}{\stackrel{K_{6}}{\leftrightarrows}} } \\
\stackrel{\leftrightarrows}{\leftrightarrows}[\text { Bridge } \cdot \operatorname{LigIV} / \mathrm{XRCC} 4 / \mathrm{XLF} \cdot \mathrm{PNKP}]
\end{aligned}
$$

When DNA lesion represents a DSB with noncohesive and/or damaged termini, small gaps can be produced at or near the site of the break (Neal and Meek 2011). The induction of such unligatable ends is more probable under exposure to densely ionizing radiation (mainly HZE-particles), than to sparsely ionizing ones, due to a larger portion of clustered DNA lesions. Consequently the filling of the occurred gaps prior to ligation is also a significant stage liable to be taken into consideration in the model.

The majority of reviewed studies indicate three main enzymes from the polymerase X (Pol X) family associated with NHEJ-dependent gap filling in mammalian cells. They include Tdt, Pol $\lambda$, and Pol $\mu$ (Ramsden 2010). Nevertheless, recent findings suggest a limited implication of these factors. It is indicated that Tdt is only expressed in developing lymphocytes where it is involved in V(D)J recombination (Neal and Meek 2011). Pol $\lambda$ and Pol $\mu$ are ubiquitously expressed, but vertebrate cells deficient in these enzymes individually or both are not significantly radiosensitive (Bertocci et al. 2006). Hence it has been suggested that Pol $\lambda$ and Pol $\mu$ are dispensable for completion of NHEJ, but they can contribute to the quality of the repair pathway (Neal and Meek 2011). Taking into account the above-mentioned results, we introduce in our model an abstract enzyme Pol possessing polymerase activity. According to (Hefferin and Tomkinson 2005), we assume that Pol binds to the previously formed [Bridge $\cdot \operatorname{LigIV} / \mathrm{XRCC} 4 / \mathrm{XLF} \cdot \mathrm{PNKP}]$ multifermental complex as an additional repair factor. After gap filling and ligation are finalized, it is accepted that this complex dissociates, leaving the recovered dsDNA site. According to our model, all considered NHEJ repair factors stay bound to a DSB region, until ligation stage is completed. Therefore the final step of this pathway can be denoted as

$$
\begin{gathered}
{[\text { Bridge } \cdot \operatorname{LigIV} / \mathrm{XRCC} 4 / \mathrm{XLF} \cdot \mathrm{PNKP}]+[\mathrm{Pol}] \underset{K_{-7}}{\stackrel{K_{7}}{\leftrightarrows}}} \\
\stackrel{K_{7}}{\leftrightarrows}[\text { Bridge } \cdot \operatorname{LigIV} / \mathrm{XRCC} 4 / \mathrm{XLF} \cdot \mathrm{PNKP} \cdot \mathrm{Pol}] \stackrel{K_{8}}{\longrightarrow} \\
\stackrel{K_{-7}}{\longrightarrow}[\mathrm{dsDNA}]+[\operatorname{LigIV} / \mathrm{XRCC} 4 / \mathrm{XLF}]+[\mathrm{Pol}]+[\mathrm{PNKP}]+ \\
+[\mathrm{DNA}-\mathrm{PKcs}]+[\mathrm{Ku}] .
\end{gathered}
$$


To simulate the above-mentioned stages of NHEJ, we used a biochemical approach based on nonlinear kinetics. A dynamic change of intracellular concentrations of main intermediate complexes can be generally expressed by the following differential equations:

$$
\frac{d X}{d t}=V_{+}\left(X_{i}, N_{0}\right)-V_{-}\left(X_{i}, N_{0}\right)
$$

where $X_{i} \quad(i=1, \ldots, n)$ is the intracellular level of the $i$-th NHEJ complex, $t$ is time, the functions $V_{+}$and $V_{-}$describe the complex accumulation and degradation, respectively. The dimensionless form of the system of ordinary differential equations (ODE) referred to simulation of NHEJ pathway as well as its parameters and initial conditions are presented in Appendix A.

2.3. Quantitative Model of the HR Pathway. Representing the second major DSB repair pathway, HR can be conceptually divided into three stages: presynapsis, synapsis, and postsynapsis (Heyer et al. 2010). In the presynaptic stage, DNA lesion is detected and processed to form an extended ssDNA region. Here, MRN (Mre11-Rad50-Nbs1) complex plays a multiply role carrying out DNA end resection and participating further excision (Lee and Paull 2004). Each component of the complex fulfills its specific function. It has been suggested that Mre11 subunit, possessing endonuclease and 3'-5' exonuclease activity, recognizes the DSB. Rad50 increases the binding activity of MRN complex with DNA. $\mathrm{Nbs} 1$ acts as a regulatory and protein recruitment module, providing interaction of MRN with a number of processing factors, including CtIP which possesses endonuclease activity, ExoI degrading DNA in the 5'- to 3'-direction, and Dna2 exhibiting helicase and exonuclease activities (Williams et al. 2010). Summarizing these data, we can describe the first stage of HR associated with action of MRN and co-factors as

$$
\begin{aligned}
& {[\mathrm{DSB}]+[\mathrm{MRN} / \mathrm{CtIP} / \text { ExoI/Dna2 }] } \stackrel{P_{1}}{\leftrightarrows}[\mathrm{DSB} \cdot \mathrm{MRN} / \mathrm{CtIP} / \text { ExoI/Dna2 }] \stackrel{P_{-1}}{\longrightarrow} \\
& \stackrel{P_{2}}{\longrightarrow}[\mathrm{ssDNA}]+[\mathrm{MRN} / \mathrm{CtIP} / \text { ExoI/Dna2 }], \quad
\end{aligned}
$$

where the resection and formation of an extended ssDNA region are combined together. Here, MRN interacting with other repair factors is considered as a single complex.

When ssDNA has been produced, the replication protein A (RPA) binds to it eliminating secondary structures and protecting single-stranded regions from other enzymatic activities. In our model, this stage is denoted by

$$
[\mathrm{ssDNA}]+[\mathrm{RPA}][\mathrm{ssDNA} \cdot \mathrm{RPA}] \text {. }
$$

Next HR step is associated with activity of Rad51, which replaces RPA forming specific nucleoprotein filaments capable to search homologous DNA sequence. 
Although RPA bound to ssDNA forms a kinetic barrier against Rad51 filaments assembly, Rad51 overcomes RPA binding with the assistance of the so-called mediator proteins. These mediator proteins are supposed to allow timely Rad51 filament formation on RPA-covered ssDNA (Heyer et al. 2010). In mammalian and human cells several proteins have been associated with Rad51 filamentation, but their exact functions are not quite intelligible. The product of the breast cancer susceptibility gene, BRCA2 (or FANCD1), and Rad51 paralogs (Rad51B, Rad51C, Rad51D, XRCC2, and XRCC3) play probably a major role in this process (Neal and Meek 2011). According to these findings, the current HR stage can be represented as

$$
\begin{aligned}
& {[\mathrm{ssDNA} \cdot \mathrm{RPA}]+[\operatorname{Rad} 51 / \operatorname{Rad} 51 \mathrm{par} / \mathrm{BRCA} 2] \underset{P_{-1}}{\stackrel{P_{1}}{\leftrightarrows}}} \\
& \underset{P_{-1}}{\stackrel{P_{1}}{\leftrightarrows}}[\mathrm{ssDNA} \cdot \mathrm{RPA} \cdot \operatorname{Rad} 51 / \operatorname{Rad} 51 \mathrm{par} / \mathrm{BRCA} 2] \stackrel{P_{5}}{\longrightarrow} \\
& \stackrel{P_{5}}{\longrightarrow}[\operatorname{Rad} 51 \text { filament }]+[\mathrm{RPA}],
\end{aligned}
$$

where Rad51par abbreviation denotes five above-mentioned Rad51 paralogs, and [Rad51 filament] defines the [ssDNA·Rad51/Rad51par/BRCA2] complex.

Further processing of a DSB occurs through the synaptic phase, in which Rad51 filament performs homology search and DNA-strand invasion generating a displacement loop (D-loop). It is shown that in human cells the search for homology occurs through the so-called "catch and release" mechanism similar to the RecA-mediated recombination in bacteria (Neal and Meek 2011). During this process, the incoming dsDNA is transiently held within the secondary DNA binding site of the Rad51 filament and, if no homology is found, the duplex is released. Then a new dsDNA segment is sampled for homology. When a homologous sequence is found, the alignment of the ssDNA and the homologous region of the incoming dsDNA occurs and it leads to synapsis and formation of DNA joints. Once the invading ssDNA binds to the complementary strand of dsDNA, the homologous DNA strand becomes excluded and D-loop arises. It is thought that $\operatorname{Rad} 54$ protein plays a role in the process stabilizing the $\operatorname{Rad} 51$ filament, enchasing D-loop formation and promoting the transition from strand invasion to DNA synthesis by dissociating Rad51 from heteroduplex DNA (Heyer et al. 2006). On the ground of the above-mentioned fact, our model assumes the following description of D-loop induction

$$
\begin{aligned}
{[\operatorname{Rad} 51 \text { filament }]+\left[\mathrm{DNA}_{\text {inc }}\right]\left[\operatorname{Rad} 51 \text { filament } \cdot \mathrm{DNA}_{\text {inc }}\right] \stackrel{P_{7}}{\longrightarrow} } \\
\stackrel{P_{7}}{\longrightarrow}[\mathrm{D}-\mathrm{loop}]+[\operatorname{Rad} 51 / \operatorname{Rad} 51 \text { par } / \text { BRCA2 }],
\end{aligned}
$$

where $\left[\mathrm{DNA}_{i n c}\right]$ defines the incoming DNA duplex, and $[\operatorname{Rad} 51$ filament $\times$ $\left.\times \mathrm{DNA}_{\text {inc }}\right]$ complex is assumed to contain $\operatorname{Rad} 54$ protein. The back reaction 
characterizes here a possible release of initially formed duplex, if no homology is found within the incoming DNA sequence.

Finally, branch migration and continued strand displacement occur in postsynapsis. Recent studies distinguishes, at least, five possible scenarios in this stage (Heyer et al. 2010). If the second end is absent, D-loop may become a full-fledged replication fork that leads to a half-crossover subpathway called break-induced replication (BIR). When a second end is available, the major scenario is represented by a process known as synthesis-dependent strand annealing (SDSA), in which a newly synthesized strain anneals with the second resected DNA strand. The subpathway occurs in a noncrossover manner, and it is often associated with somatic cells. Three other possible variants of DSB processing proceed through formation of double Holiday junction $(\mathrm{dHJ})$ and its subsequent resolution. Two of them follow the noncrossover scenario, and the last one occurs through the crossover.

Although the mentioned postsynaptic subpathways have been distinguished, their enzymatic requirements, as well as the exact molecular mechanisms remain under debate. The time-course of these stages is also insufficiently studied experimentally. Therefore to adequately simulate postsynaptic processes, we assume a more abstract approach, grouping all possible scenarios into two main subpathways. The first of them combines the subpathways which proceed through the formation of $\mathrm{dHJ}$. Based on this assumption, D-loop irreversibly transforms to $\mathrm{dHJ}$ and proceeds to the following recovery of DNA:

$$
[\mathrm{D}-\mathrm{loop}] \stackrel{P_{8}}{\longrightarrow}[\mathrm{dHJ}] \stackrel{P_{9}}{\longrightarrow}[\mathrm{dsDNA}]+\left[\mathrm{DNA}_{\text {inc }}\right] \text {. }
$$

In this formula both the processes are simply described by transitions from one intermediate state to another with corresponding average rate constants.

The second assumed subpathway merges BIR and SDSA scenarios. In this case, the final repair step is described by a direct transition of D-loop to recovered dsDNA with the rate constant, which differs from $P_{8}$ and $P_{9}$

$$
[\text { D-loop }] \stackrel{P_{10}}{\longrightarrow}[\mathrm{dsDNA}]+\left[\mathrm{DNA}_{\mathrm{inc}}\right] \text {. }
$$

Since functions of enzymes involved in these stages are not well identified, we do not take into consideration any proteins in Eqs. (14) and (15).

On the basis of suggested kinetic schemes, time-courses of induction and dissociation of the mentioned HR complexes are simulated by the usage of differential equations similar to Eq. (9) with new $Y$ variables

$$
\frac{d Y}{d t}=V_{+}\left(Y_{j}, N_{0}\right)-V_{-}\left(Y_{j}, N_{0}\right) \text {. }
$$

$Y_{j}(j=1, \ldots, m)$ here is the intracellular level of the $j$-th HR enzyme complex. The dimensionless form of ODE system for simulation of HR, its parameters, and initial conditions are stated in Appendix B. 
2.4. Quantitative Model of the SSA Pathway. SSA occurs when an induced DSB is located between two repetitive sequences oriented in the same direction. Although the mechanistic basis of this pathway is mostly well studied in yeasts, recent findings allow one to formulate molecular models of SSA in mammalian and human cells as well. This process can be conceptually divided into four main stages, namely end resection, annealing, second resection, and ligation. The SSA end resection is similar to that in HR and occurs through the processing of a DSB by the MRN complex (Symington 2002). The generated ssDNA overhangs then become coated and stabilized by RPA. In our model, we assume that these two steps occur in the same manner, as during HR. Therefore Eqs. (10), (11) can be used to describe the initiation of SSA.

In the following annealing stage, in which the flap structure is formed by the annealing of two repetitive sequences, the key role belongs to Rad52 protein (Singleton et al 2002). By this reason, SSA represents a Rad51 independent pathway in contrast to HR. Possessing ssDNA annealing activity, Rad52 forms heptamer ring structures which are bound to the resected DNA overhangs. In our work, this step is denoted by

$$
[\mathrm{ssDNA} \cdot \mathrm{RPA}]+[\operatorname{Rad} 52] \underset{P_{-1}}{\stackrel{P_{1}}{\leftrightarrows}}[\mathrm{ssDNA} \cdot \mathrm{RPA} \cdot \operatorname{Rad} 52]
$$

where the $[\mathrm{ssDNA} \cdot \mathrm{RPA}]$ complex is the same as in Eq. (11).

The junction between Rad52 heptamer rings and each ssDNA termini allows single-strand tails to be turned outward that promotes paring of complementary DNA regions. We suggest the following quantitative representation of the flap structure formation

$$
[\mathrm{ssDNA} \cdot \mathrm{RPA} \cdot \operatorname{Rad} 52]+[\mathrm{ssDNA} \cdot \mathrm{RPA} \cdot \operatorname{Rad} 52] \stackrel{\mathrm{Q}_{2}}{\longrightarrow}[\mathrm{Flap}]+[\mathrm{RPA}],
$$

where [Flap] denotes the joint structure with two flapped ends, as is depicted in Figure 1. We also assume that in this process RPA unbinds from the regions which undergo pairing. At the same time, according to findings stated in (Van Dyck et al. 2001), Rad52 remains bound to the produced DNA intermediate after annealing.

In the second resection stage, the flapped ends are cut off by the ERCC1/XPF endonuclease (Sargent et al. 2000). It is shown that ERCC1/XPF possibly binds to the flap structure by interacting with Rad52 (Motycka et al. 2004). The cleavage of ssDNA tails results in formation of the dsDNA structure which contains nicks at sites of flap cutting. This SSA step can be represented by the following enzymatic reaction:

$$
\begin{array}{r}
{[\text { Flap }]+[\text { ERCC1/XPF }] \underset{\mathrm{P}_{-1}}{\stackrel{\mathrm{P}_{1}}{\leftrightarrows}}[\text { Flap } \cdot \text { ERCC } 1 / \mathrm{XPF}] \stackrel{Q_{4}}{\longrightarrow}\left[\mathrm{dsDNA}_{\text {nicks }}\right]+} \\
+[\mathrm{Rad} 52]+[\mathrm{ERCC} 1 / \mathrm{XPF}]
\end{array}
$$


According to our assumption, Rad52 and ERCC1/XPF dissociate from the processing site.

In the ligation stage, the produced nicks are joined by DNA ligase. The exact enzyme responsible for the ligation stage in mammalian and human cells is still under debate, in vitro studies, however, nominate DNA ligase III (LigIII) is the most probable candidate for this (Gottlich et al. 1998). We also believe that the ligation step is occurred with LigIII. Therefore the formation of the final repair product, [dsDNA], can be denoted by

$$
\begin{aligned}
{\left[\mathrm{dsDNA}_{\text {nicks }}\right]+[\mathrm{LigIII}] \underset{P_{-1}}{\stackrel{P_{1}}{\leftrightarrows}}\left[\mathrm{dsDNA}_{\text {nicks }} \cdot \operatorname{LigIII}\right] \stackrel{Q_{6}}{\longrightarrow} } \\
\stackrel{Q_{6}}{\longrightarrow}[\mathrm{dsDNA}]+[\mathrm{LigIII}] .
\end{aligned}
$$

The simulation of the kinetics of the complexes, which take part in SSA, is performed in the same ways as for NHEJ and HR with introducing new $Z$ variables

$$
\frac{d Z}{d t}=V_{+}\left(Z_{h}, N_{0}\right)-V_{-}\left(Z_{h}, N_{0}\right)
$$

In Eq. (15), $Z_{h}(h=1, \ldots, l)$ is the intracellular level of the $h$ th SSA enzyme complex. A dimensionless form of the ODE system for simulation of this repair pathway, as well as its parameters and initial conditions, are stated in Appendix C.

2.5. A Model for $\gamma$-H2AX Foci Induction. When $\gamma$-H2AX foci are used as a biomarker of radiation exposure, the estimation of the repair time-course is usually performed by the quantification of foci per nucleus at corresponding times after irradiation. In this case, experimental results reflect a certain average rate of $\mathrm{DSB}$ repair occurring with either $\mathrm{Ku}$ - or MRN-initiated pathways. To compare calculated results with this experimental data, we suggest the following model for kinetics of radiation-induced $\gamma$ - $\mathrm{H} 2 \mathrm{AX}$ foci.

The induction of $\gamma$-H2AX foci after DNA damage occurs due to the phosphorylation of the histone variant $\mathrm{H} 2 \mathrm{AX}$ by phosphatidyl-inosito-3 kinase (PIKK) family of proteins which include DSB repair enzymes, ataxia telangiectasia mutated (ATM), DNA-PKcs and ATM and RAD3-related (ATR) (Mah et al. 2010). Recent studies suggest that mainly two of them, DNA-PKcs and ATM, affect the balance between $\mathrm{Ku}$ - and MRN-dependent pathways and that DNA-PKcs controls ATM levels independently of DNA-PKcs kinase activity (Shrivastav et al. 2009). The fact can serve as an evidence indicating a major contribution of DNA-PKcs to the process of radiation-induced $\gamma-\mathrm{H} 2 \mathrm{AX}$ foci formation. On the basis of these facts, we simulate foci induction by Michaelis-Menten kinetics summing up all active forms of DNA-PKcs, which are considered in the model, as it was done in (Cucinotta et al. 2008) 


$$
V_{\gamma-\mathrm{H} 2 \mathrm{AX}}+=\frac{K_{9}[\mathrm{Sum}][\mathrm{H} 2 \mathrm{AX}]}{K_{10}+[\mathrm{Sum}]},
$$

where $[\mathrm{H} 2 \mathrm{AX}]$ is the level of histone variant $\mathrm{H} 2 \mathrm{AX}$ and

$$
\begin{aligned}
& {[\text { Sum }]=\left[\text { DSB } \cdot \text { DNA-PK } / \text { Art }^{\mathrm{P}}\right]+[\text { Bridge }]+} \\
& +[\text { Bridge } \cdot \text { LigIV } / \text { XRCC } 4 / \text { XLF }]+[\text { Bridge } \cdot \text { LigIV } / \text { XRCC } 4 / \text { XLF } \cdot \text { PNKP }]+ \\
& +[\text { Bridge } \cdot \text { LigIV } / \text { XRCC } 4 / \text { XLF } \cdot \text { PNKP } \cdot \text { Pol }] .
\end{aligned}
$$

The precise mechanism of $\gamma$-H2AX foci dephosphorylation is not perfectly understandable yet. Thus, in our model, we simply consider that the decrease of foci is proportional to the amount of repaired DNA and its spontaneous decay with the corresponding rate constants $K_{11}$ and $K_{12}$

$$
V_{\gamma-\mathrm{H} 2 \mathrm{AX}-}=\mathrm{K}_{11}[\mathrm{dsDNA}]+\mathrm{K}_{12}[\gamma-\mathrm{H} 2 \mathrm{AX}] .
$$

The final differential equation for the time-course of $\gamma-\mathrm{H} 2 \mathrm{AX}$ foci is given in Eqs. (A.1) of Appendix A.

To simplify the models described in Subsecs. 2.2-2.5, the concentrations of all proteins involved in the repair process were accepted constant and much greater than the number of initially induced DSBs, as it was done in (Cucinotta et al. 2008). Consequently, the corresponding differential equations for $X_{1}, X_{3}$, $X_{7}, X_{9}, X_{11}, Y_{1}, Y_{4}, Y_{6}, Y_{9}, Z_{1}, Z_{4}$, and $Z_{7}$ were omitted in Eqs. (A.1), (B.1), and (C.1). Performing calculations only for intermediate complexes simplifies significantly the computation procedure. A constant value for all proteins was set the same and it equals the total cellular concentration of Ku (see Appendix A), according to the assumption in (Cucinotta et al. 2008).

\section{EVALUATION OF THE MODEL PARAMETERS}

The majority of the rate constants of enzymatic reactions were determined by fitting the corresponding model curves produced using Eqs. (A.1), (B.1), and (C.1) to the experimental data on kinetics of different stages of DSB repair. Other parameters characterizing the regularities of DSB induction were obtained directly from experimental measurements reviewed in the literature.

3.1. Parameters of the Model for DSB Induction. In order to estimate $\alpha(L)$ we used three sets of experimental data on DSB induction in GM38 and GM57 lines of human skin fibroblasts within the LET values ranged from 0.2 to $440 \mathrm{keV} / \mu \mathrm{m}$ (Rydberg 1996; M. Lobrich 1996; E.Hogland 2000). The DSB yield measured in these studies as $\mathrm{Gy}^{-1}$ per $10^{9}$ bp was recalculated to $\mathrm{Gy}^{-1}$ per cell taking into account that a diploid human cell in G1 phase contains about 
$5 \cdot 10^{9}$ bp of DNA (Rydberg 1996). The experimental data were approximated by the exponential function $\alpha(L)=a \exp (-b L)$ to obtain a continuous function within the stated LET range. The parameters of the function given in Table A.1 of Appendix A were evaluated by adjusting the curve for $\alpha(L)$ to the results of the above mentioned experimental measurements (Fig. 2).

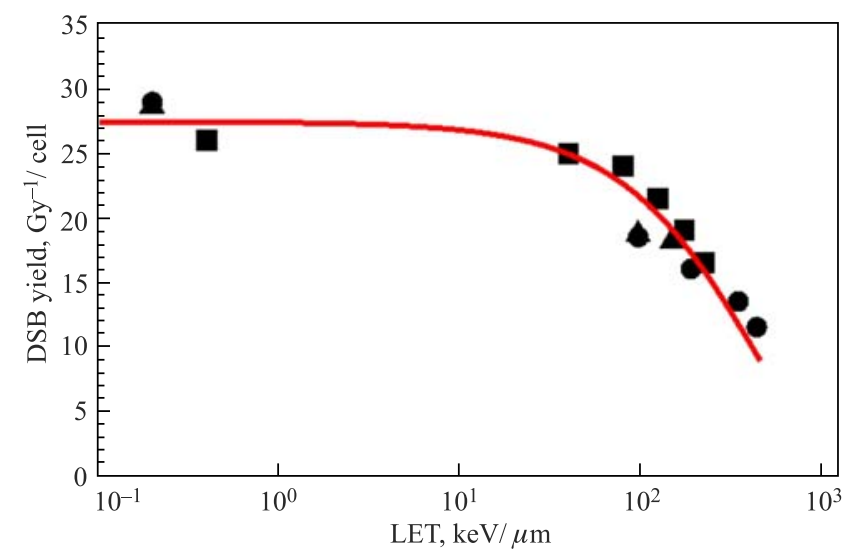

Fig. 2. Yields of DNA DSB in different human cells estimated by the model $\left(\mathrm{Gy}^{-1}\right.$ per cell). The data is calculated for the LET range of $0.2-440 \mathrm{keV} / \mu \mathrm{m}$. The symbols are the experimental data for - - primary human skin fibroblasts (GM38) irradiated by X-rays, ${ }^{14} \mathrm{~N}$, and ${ }^{56} \mathrm{Fe}$ (Rydberg 1996); $\mathbf{\Delta}$ - primary human skin fibroblasts (GM38) irradiated by X-rays, ${ }^{14} \mathrm{~N}$, and ${ }^{56} \mathrm{Fe}$ (Lobrich et al. 1996); - normal human skin fibroblasts (GM5758) irradiated by $\gamma$-rays $\left({ }^{60} \mathrm{Co}\right),{ }^{4} \mathrm{He}$, and ${ }^{14} \mathrm{~N}$ (Hogland et al. 2000)

$N_{i r}$, the fraction of irreparable DSBs, is set in accordance with the available experimental data on percentage of $\gamma-\mathrm{H} 2 \mathrm{AX}$ foci remained $24 \mathrm{~h}$ after irradiation. The values of this parameter presented in Table A.2 are assumed to be dependent on the type of radiation and repair status of cells.

3.2. Ku Binding Parameters. The first group of parameters was evaluated by fitting the model curve for $X_{2}$ to experimental data on the binding of $\mathrm{Ku}$ to DSB after ultrasoft X-ray (USX) irradiation of Chinese hamster lung fibroblasts with doses of $27 \mathrm{~Gy}$ and $137 \mathrm{~Gy}$ (Reynolds et al. 2012). Since these data is measured in the Ku80-EGFP fluorescently tagged cells, only $K_{1}, K_{-1}$, $K_{2}$, and $K_{-2}$ parameters were evaluated by using Eqs. (A.1) and considering the computation results for [DSB $\mathrm{Ku}$ ] complex. The relation of these dimensional parameters to dimensionless ones $\left(k_{i}\right)$ and the scaled variables $\left(x_{j}\right)$ are presented in the corresponding section of Appendix A. In order to estimate the first group of parameters, we set other reaction rate constants in Eqs. (A.1) and the initial conditions of all intermediate complexes as zero. In such circumstances, Eqs. (B.1) 


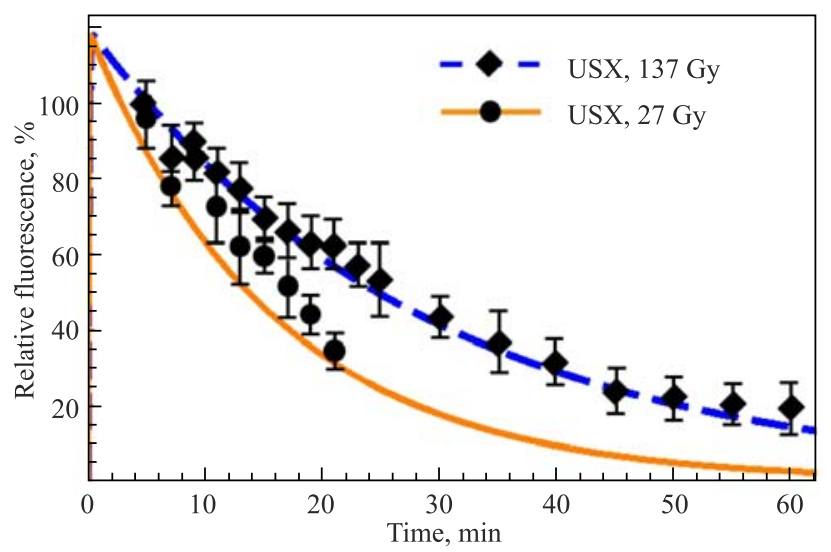

Fig. 3. Time-courses of Ku binding to DSB after exposure to USX at the doses of 27 and 137 Gy. The curves are the calculated results; the symbols are the experimental data on fluorescence in Ku80-EGFP-tagged Chinese hamster lung fibroblasts after exposure to USX at the corresponding doses ( \pm SEM) (Reynolds et al. 2012). The maximum values of computed curves exceed $100 \%$ at early stages, due to divergences in scaling of the data in the experiment and in our calculations. The results of experimental measurements are normalized per the fluorescence level observed at $5 \mathrm{~min}$ after beginning of the detection, while the computed curves are scaled per the value at $30 \mathrm{~s}$ that corresponds to maximal recruitment of $\mathrm{Ku}$

and Eqs. (C.1) were not included into calculation procedure, since activity of $\mathrm{Ku}$ refers mainly to NHEJ. The difference in radiation dose was taken into account by setting the corresponding values for $D$ parameter in Eq. (1). The LET and $N_{i r}$ parameter for USX were set as it is stated in Table A.2. The results of the parameter evaluation are presented in Fig. 3 in comparison with the experimental data for two values of dose. The computed curves were normalized to the value of $X_{2}$ at $30 \mathrm{~s}$ after irradiation that corresponds to the maximal recruitment of $\mathrm{Ku}$ according to (Taleei and Nikjoo 2013). In our work, the NewtonRaphson method was applied for curve fitting. The obtained values of $K_{1}$, $K_{-1}, K_{2}$, and $K_{-2}$ parameters are presented in Table A. 1.

3.3. DNA-PKes Recruitment Parametres. The second group of parameters, which includes $K_{3}, K_{4}, K_{-4}, K_{5}, K_{-5}, K_{6}, K_{-6}, K_{7}$, and $K_{-7}$, was estimated by fitting the model curve, corresponding to the sum of the solutions for $X_{5}, X_{6}$, $X_{8}, X_{10}$, and $X_{12}$, to the experimental data on the recruitment of DNA-PKcs to DSBs, induced by $\gamma$-rays and $1 \mathrm{GeV} / \mathrm{u}{ }^{56} \mathrm{Fe}$ particles at the dose of $1 \mathrm{~Gy}$ (Asaithamby et al. 2008). The values of the $K_{1}, K_{-1}, K_{2}$, and $K_{-2}$ parameters were taken from the previous fitting stage, and the initial conditions were set in the same manner as in Subsec.3.2. The combination of solutions is exploited to provide an adequate account of all active forms of DNA-PKcs which may con- 


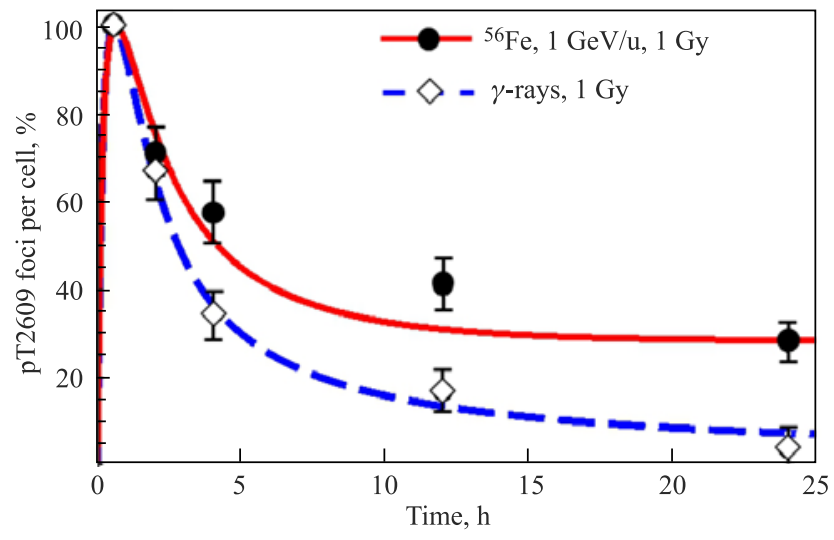

Fig. 4. Time-courses of DNA-PKcs recruitment to a DSB site after exposure to $\gamma$-rays $\left({ }^{137} \mathrm{Cs}\right)$ and $1 \mathrm{GeV} / \mathrm{u}{ }^{56} \mathrm{Fe}$ ions at the dose of $1 \mathrm{~Gy}$. The calculated curves are compared to experimental data on pT2609 foci induction in human skin fibroblasts (HSF42) after irradiation with corresponding doses (symbols) (Asaithamby et al. 2008). The error bars represent SEM

tribute to the fluorescent signal measured in the experiment. Since we assume that the considered NHEJ enzymes remain bound to a DSB site until end-joining, all intermediate complexes containing the phosphorylated DNA-PKcs are referred to its active forms. Therefore the complexes designated as $\left[\mathrm{DSB} \cdot \mathrm{DNA}-\mathrm{PK} / \mathrm{Art}^{\mathrm{P}}\right]$, [Bridge], [Bridge $\cdot \operatorname{LigIV} / \mathrm{XRCC} 4 / \mathrm{XLF}], \quad[$ Bridge $\cdot \operatorname{LigIV} / \mathrm{XRCC} 4 / \mathrm{XLF} \times$ $\times \mathrm{PNKP}]$, and $[$ Bridge $\cdot \operatorname{LigIV} / \mathrm{XRCC} 4 / \mathrm{XLF} \cdot \mathrm{PNKP} \cdot \mathrm{Pol}]$ are taken into consideration. In our analysis we fit the model curve to the experimental data on quantification of pT2609 foci produced in HSF42 cells using anti-pT2609 (phospho-specific DNA-PKcs) monoclonal antibodies (Asaithamby et al. 2008). The obtained values of the $K_{3}, K_{4}, K_{-4}, K_{5}, K_{-5}, K_{6}, K_{-6}, K_{7}$, and $K_{-7}$ parameters were similar both for $\gamma$-rays and ${ }^{56} \mathrm{Fe}$ particles (Table A. 1). The computed curves compared to experimental data are presented in Fig. 4. The difference between the results for two types of radiations is achieved by variation of $N_{i r}$ parameter in accordance with the values mentioned in Table A.2. The calculated results are expressed as the percentage of pT2609 foci scaled per the number of foci at the time of $0.5 \mathrm{~h}$ after irradiation, as it was done in the experiment (Asaithamby et al. 2008).

3.4. RPA and Rad51 Involvement Parameters. The next group of parameters was evaluated by fitting the corresponding model curves to the experimental data on RPA and Rad51 foci induction after irradiation of different cell types with X-rays, $\gamma$-rays, and $1 \mathrm{GeV} / \mathrm{u}{ }^{56} \mathrm{Fe}$ ions.

At first, the model curve for the sum of the solutions for $Y_{5}, Y_{7}$, and $Z_{2}$ was fitted to the percentage of cells with RPA foci measured in WIL-2NS human 
B-lymphoblast cell culture after exposure to X-rays at the dose of 4 Gy (MacPhail and Olive 2001). The curve computed in this way corresponds to the combination of solutions for [ssDNA - RPA], [ssDNA - RPA - Rad51/Rad51par/BRCA2], and $[\mathrm{ssDNA} \cdot \mathrm{RPA} \cdot \mathrm{Rad} 52]$ complexes. It reflects all possible sources of fluorescence in this case. This fitting step results in determining of $P_{1}, P_{-1}, P_{2}$, $P_{3}, P_{-3}, P_{4}, P_{-4}, P_{5}, Q_{1}, Q_{-1}$, and $Q_{2}$ parameters of the model by considering all three systems of equations Eqs. (A. 1), (B.1), (C.1) with zero initial conditions for the intermediate complexes and the corresponding values of $N_{i r}$ and $D$ (Table A.2). The calculated curve (Fig. 5) was normalized per maximum value of solutions for the sum of $Y_{5}, Y_{7}$, and $Z_{2}$ obtained at $\sim 5 \mathrm{~h}$ after irradiation.

The parameters $P_{6}, P_{-6}$, and $P_{7}$ were evaluated by fitting the model curve for the sum of the solutions for $Y_{7}, Y_{8}$, and $Y_{10}$ to experimental data on $\operatorname{Rad51}$ foci remaining in HF19 and V79-4 cells after exposure to $1 \mathrm{GeV} / \mathrm{u}{ }^{56} \mathrm{Fe}$ ions at the dose of $1 \mathrm{~Gy}$ (Anderson et al. 2010) and $\gamma$-rays at the dose of $10 \mathrm{~Gy}$, respectively (Harper et al. 2010). The values of the previously obtained $P_{4}, P_{-4}$, and $P_{5}$ parameters, which are also referred to the activity of Rad51, were verified for the compliance with this data. As in the preceding fitting stage, the combination of solutions was applied to consider all possible sources of the fluorescent signal which corresponds to induction of Rad51 foci. Thus, there have been considered the complexes named as [ssDNA - RPA - Rad51/Rad51par/BRCA2], [Rad51 filament], and $\left[\operatorname{Rad} 51\right.$ filament $\left.\cdot \mathrm{DNA}_{\mathrm{inc}}\right]$. In order to acquire the values of the mentioned parameters, Eqs.(A.1), (B.1), and (C. 1) were processed simultaneously. Moreover, the reaction rates from previous fitting stages were exploited. The initial conditions for the intermediate complexes were also taken

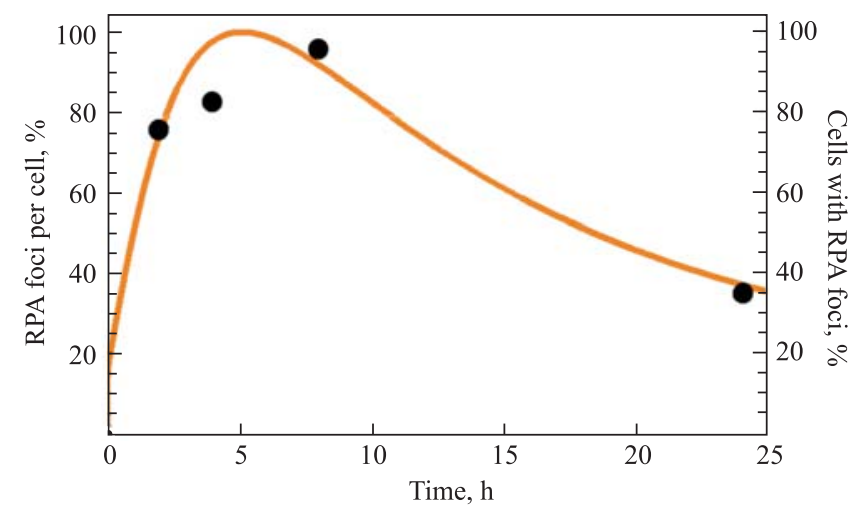

Fig. 5. Time-course of RPA recruitment after irradiation with X-rays at the dose of 4 Gy. The calculated curve is compared to experimental data on the percentage of cells with RPA foci after the exposure of WIL-2NS lymphoblast to X-rays at the corresponding dose (symbols) (MacPhail and Olive 2001). The left scale refers to the calculated value of RPA foci per cell; the right scale relates to the measured percentage of cell with foci 


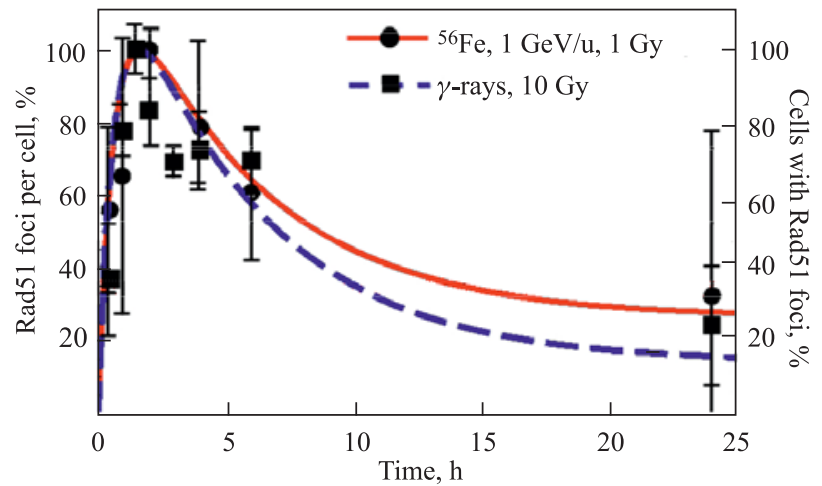

Fig. 6. Time-courses of Rad51 recruitment after exposure to $1 \mathrm{GeV} / \mathrm{u}{ }^{56} \mathrm{Fe}$ ions (1 Gy) and $\gamma$-rays (10 Gy). The curves are the calculated results; $\bullet$ are the scaled experimental data on relative number of cells with Rad51 foci in HF19 human fibroblasts after irradiation with $1 \mathrm{~Gy}$ of ${ }^{56} \mathrm{Fe}$ ions (Anderson et al. 2010); $\mathbf{\square}$ are the scaled experimental data on the average number of Rad51 foci per cell in Chinese hamster lung fibroblast (V79-4) after exposure to 10 Gy of $\gamma$ radiation (Harper et al. 2010)

as zero. The values of the $N_{i r}$ parameter were set up according to the type of radiation (Table A.2). The different doses of radiations were also taken into account by assigning the corresponding values for $D$ parameter in Eq. (1). In the case of ${ }^{56} \mathrm{Fe}$ ions, we fit the model curve to the data on the percentage of the cells with Rad51 tracks observed in the experiment, assuming that the remaining of these cells is proportional to the remaining of Rad51 foci in each cell. The obtained values of the $P_{6}, P_{-6}$, and $P_{7}$ parameters are presented in Table A.1 and their scaling is shown in Appendix B. The correspondence of the calculated curves to the experimental data is demonstrated in Fig. 6, in which we scale the calculated and measured data per their maximal values measured $2 \mathrm{~h}$ and $1.5 \mathrm{~h}$ after irradiation with ${ }^{56} \mathrm{Fe}$ and $\gamma$-rays, respectively.

3.5. $\gamma$-H2AX Foci Induction Parameters. The last group of parameters which includes $K_{8}, K_{9}, K_{10}, K_{11}, K_{12}, P_{8}, P_{9}, Q_{3}, Q_{-3}, Q_{4}, Q_{5}, Q_{-5}$, and $Q_{6}$ was evaluated by fitting the model curve for $X_{14}$ to different sets of experimental data on $\gamma$-H2AX foci remaining in primary normal human skin broblasts (HSF42) after various radiation exposures (Asaithamby et al. 2008). In this case, the ODE systems Eqs.(A.1), (B.1), and (C.1) were processed simultaneously with the corresponding values of $N_{i r}$ and $D$, zero initial conditions for all intermediate complexes and reaction rates estimated at the previous fitting stages.

The parameters were evaluated in the manner satisfying the experimental measurements for both low- and high-LET radiations. For the former ones, the reaction rates were checked against the data on the exposure to $\gamma$-rays, when for the latter ones, the data on irradiation with ${ }^{16} \mathrm{O},{ }^{28} \mathrm{Si}$, and ${ }^{56} \mathrm{Fe}$ ions were 


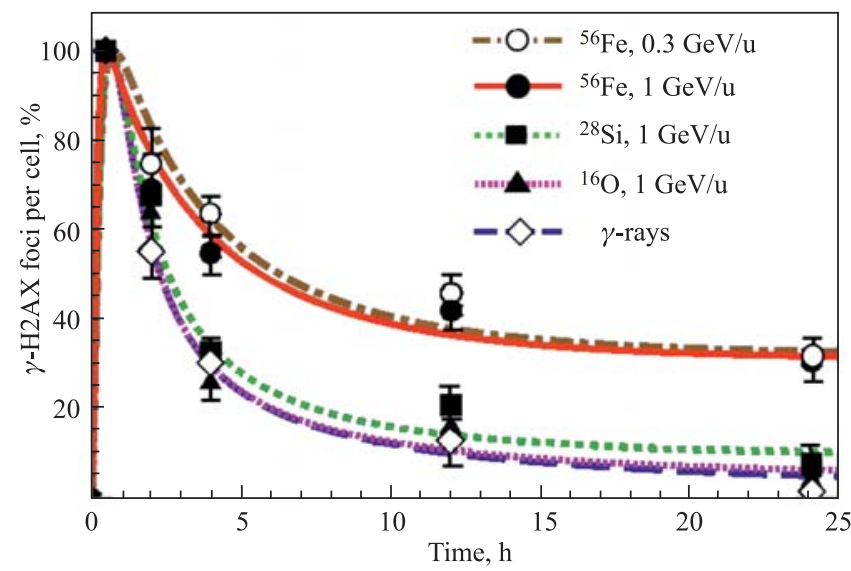

Fig. 7. Time-courses of $\gamma-\mathrm{H} 2 \mathrm{AX}$ remaining after exposure to $1 \mathrm{~Gy}$ of iron, silicon, oxygen particles, and $\gamma$-rays. The curves are the calculated results; symbols are the experimental data referred to irradiation of human skin fibroblasts (HSF42) (Asaithamby et al. 2008). The error bars represent SEM

used. Figure 7 represents the results of curve fitting in comparison with the experimental data obtained after exposure of HSF42 cells to the above-mentioned radiations at the dose of $1 \mathrm{~Gy}$. The parameters estimated in this step are presented in Table A. 1. The scaling procedure for them is shown in Appendixes A-C.

In the equation for $\gamma-\mathrm{H} 2 \mathrm{AX}$ foci, we introduced the dependence of Michaelis constant $K_{10}$ on radiation LET and repair status of cells through $N_{i r}$. A number of experimental studies suggest that induced DSBs can be attempted to be repaired via one pathway at first, and then, if it fails, become a substrate for another system (Shibata et al. 2011). Since it is impossible to identify the exact stage at which an irrepairable lesion stops its contribution to the work of a repair system, but continues its influence on fluorescent signal from $\gamma-\mathrm{H} 2 \mathrm{AX}$ foci, we suggest using the following function for the Michaelis constant: $K_{10}=1.93 \cdot 10^{-7} / N_{i r} \mathrm{M}$. The coefficient of this function was obtained during the curve fitting.

\section{KINETICS OF $\gamma$-H2AX FOCI IN REPAIR-DEFICIENT CELLS}

4.1. $\gamma$-H2AX Foci Remaining in NHEJ-Defective Cells. With the help of our model, we calculated the time-course of $\gamma-\mathrm{H} 2 \mathrm{AX}$ foci remaining in cells defective in either DNA-PKcs or LigIV after the exposure to low- and high-LET radiations. Figure 8 shows the simulation results compared to the experimental data for DNA-PKcs-deficient V3 cells of Chinese hamster irradiated with Xrays ( $D=1 \mathrm{~Gy}$ ) (Rothkamm et al. 2003) and normal human skin fibroblasts 


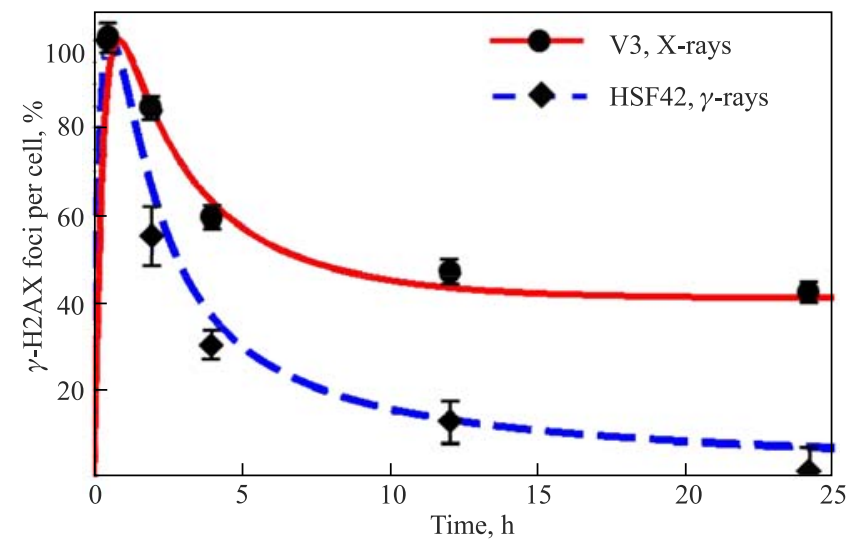

Fig. 8. Time-courses of $\gamma$-H2AX remaining in DNA-PKcs-defective V3 and normal HSF42 cells exposed to sparsely ionizing radiations at the dose of $1 \mathrm{~Gy}$. The curves are the calculated results for $\mathrm{X}$ - and $\gamma$-rays; $\forall$ are the experimental data on foci kinetics in HSF42 cells (Asaithamby et al. 2008); - are the experimental data on foci kinetics in DNA-PKcs-deficient V3 cells (Rothkamm et al. 2003). The error bars represent SEM

HSF42 exposed to $\gamma$-rays at the same dose (Asaithamby et al. 2008). In order to obtain these curves, we used the NHEJ, HR, and SSA models (Eqs. (A. 1), (B. 1), and (C. 1)) with zero initial conditions for all intermediate complexes and corresponding values of $N_{i r}$ (Table A.2). In our work, solving of ODE systems is performed with the help of the fourth-order Runge-Kutta method. The reaction rates were set according to the previously described curve fitting. In order to demonstrate the inhibited activity of DNA-PKcs we presume its initial value to be $X_{3}(0)=2.3 \cdot 10^{-12} \mathrm{M}$ which corresponds to 1 molecule per cell instead of 400000 molecules per cells $\left(9.19 \cdot 10^{-7} \mathrm{M}\right)$ assigned for other proteins.

A similar procedure was used to reconstruct the remaining of $\gamma-\mathrm{H} 2 \mathrm{AX}$ foci observed in LigIV-defective primary human fibroblasts (180BR) after irradiation with X-rays, $0.029 \mathrm{GeV} / \mathrm{u}{ }^{12} \mathrm{C}$ ions $(\mathrm{LET}=70 \mathrm{keV} / \mu \mathrm{m})$, and $0.5 \mathrm{GeV} / \mathrm{u}{ }^{56} \mathrm{Fe}$ ions $(\mathrm{LET}=200 \mathrm{keV} / \mu \mathrm{m})$ at the dose of $2 \mathrm{~Gy}$. The computed curves were compared to the experimental data on the rejoining of chromosomal breaks measured with the premature chromosome condensation (PCC) (Fig. 9, a) (Okayasu 2012). In this case, the initial condition for LigIV was set as $X_{7}(0)=2.3 \cdot 10^{-12} \mathrm{M}$ and the $N_{i r}$ was assigned as it is stated in Table A.2. With the purpose of demonstrating the difference between mutated and normal cells, we also reconstructed the kinetics of $\gamma-\mathrm{H} 2 \mathrm{AX}$ foci in normal human lung fibroblasts (HFL III) estimated in the same experiment (Okayasu 2012) (Fig. 9,b). Since the repair kinetics measured by PCC method differs usually from the one accessed with $\gamma-\mathrm{H} 2 \mathrm{AX}$ foci, we scale the calculated curves in Fig. $9, a, b$ by a factor of 2 . 
4.2. Kinetics of $\gamma-\mathrm{H} 2 \mathrm{AX}$ Foci Remaining in HR- and SSA-Defective Cells. In this section, we present the results of the calculations for the cells defective in either HR or SSA functions. Figure 10 depicts the computed foci remaining in irradiated BRCA2-deficient and normal cells in comparison with the experimental data obtained with BRCA2 ${ }^{-}$HSC62 and wild-type HSF1 cells in G2 phase (Shibata et al. 2011). The calculation is performed for the case of exposure to $\mathrm{X}$-rays and $9.8 \mathrm{MeV} / \mathrm{u}^{12} \mathrm{C}$ ions $(\mathrm{LET}=170 \mathrm{keV} / \mu \mathrm{m})$ at the dose of $2 \mathrm{~Gy}$ in
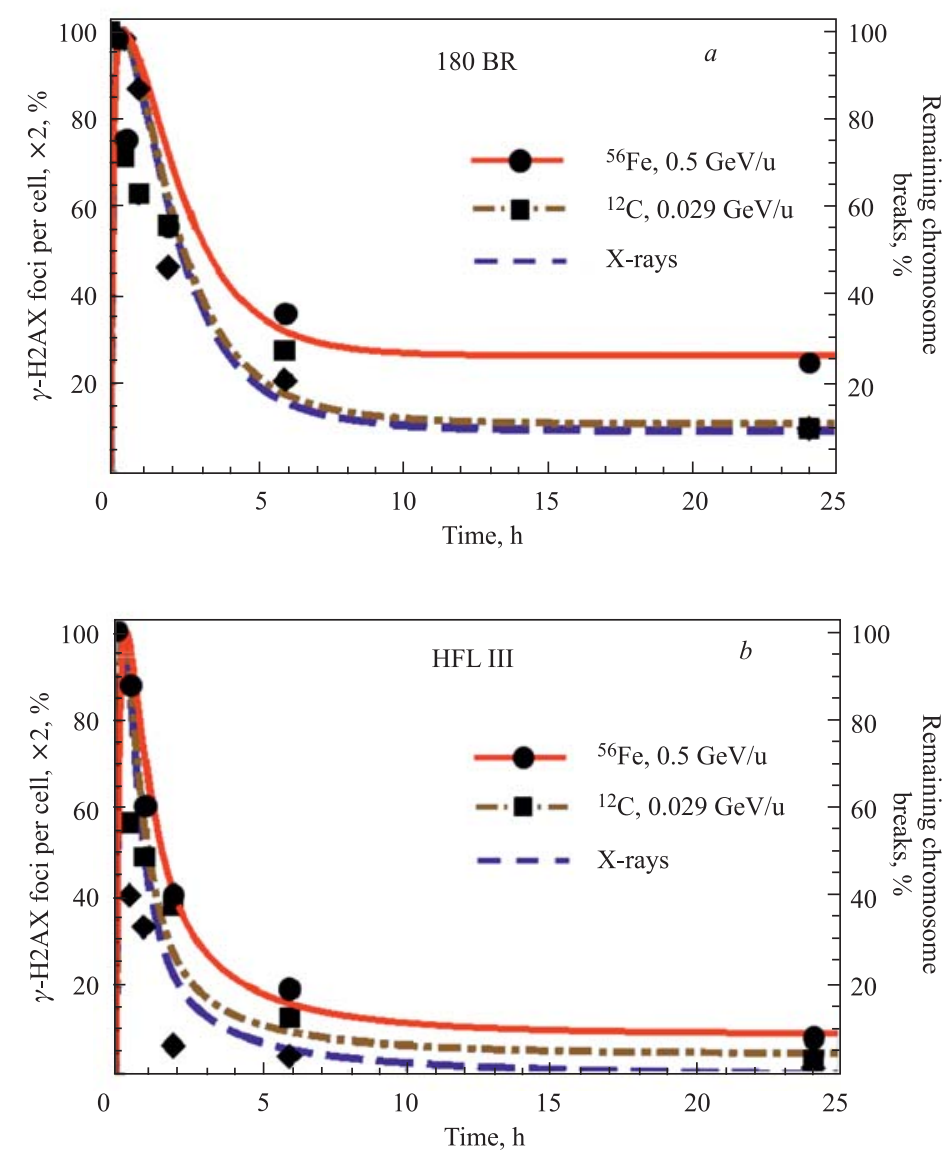

Fig. 9. Time-courses of $\gamma$-H2AX remaining in LigIV-defective primary human fibroblasts (180BR) (a) and normal human lung fibroblasts (HFL III) (b) after irradiation with X-rays, $70 \mathrm{keV} / \mu \mathrm{m}$ carbon, and $200 \mathrm{keV} / \mu \mathrm{m}$ iron ions at the dose of $2 \mathrm{~Gy}$. The curves are the calculated results; the symbols are the experimental data (Okayasu 2012). The scaled factor of 2 is introduced to compare the calculated kinetics of $\gamma-\mathrm{H} 2 \mathrm{AX}$ foci remaining to results of measurements with PCC 


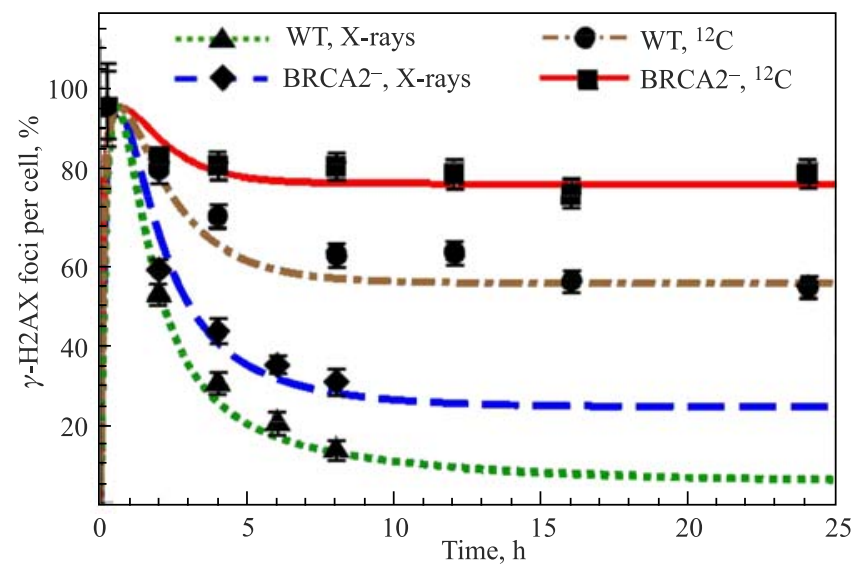

Fig. 10. Time-courses of $\gamma-\mathrm{H} 2 \mathrm{AX}$ remaining in BRCA2-defective and wild-type (WT) cells after exposure to X-rays and $9.8 \mathrm{MeV} / \mathrm{u}{ }^{12} \mathrm{C}$ ions $(\mathrm{LET}=170 \mathrm{keV} / \mu \mathrm{m})$ at the dose of $2 \mathrm{~Gy}$. The curves are the calculated results; the symbols are the experimental data for BRCA2 ${ }^{-}$HSC62 and normal HSF1 cells in G2 phase (Shibata et al. 2011). The error bars represent SEM

consistency with the experiment. In Fig. 10 the computed curves are produced by simultaneous solving of Eqs. (A. 1), (B.1), and (C.1) with the initial levels of repair complexes identical to the case of wild-type cells. The values of the $N_{i r}$ parameter are set in accordance with Table A.2. Since BRCA2-defective cells fail to load Rad51, we have set zero for the reaction rate $P_{4}$ responsible for $\operatorname{Rad} 51$ filament formation. It results in the same levels of persisted $\gamma-\mathrm{H} 2 \mathrm{AX}$ foci as it is assessed in experiment.

In order to reconstruct the time-course of $\gamma$-H2AX foci remaining in SSAdefective cells, we place the initial condition for ERCC1/XPF complex as $Z_{4}(0)=$ $2.3 \cdot 10^{-12} \mathrm{M}$. The values of the reaction rates were chosen with regard to the wildtype cells. The initial conditions for all intermediate complexes were set zero. Since there is a shortage of experimental data on $\gamma$-H2AX foci remaining induced by high-LET radiation in SSA-defective cells, we made calculations for $\gamma$-rays ( $D=2$ Gy). In this case, the value of $N_{i r}$ parameter was set as it indicated in Table A.2. The computed curves presented in Figure 11 are compared with the results of the measurements performed with XPF-deficient human fibroblasts (XFE) and $\mathrm{Erccl}^{-/-}$mouse embryonic fibroblasts (MEFs) (Ahmad et al. 2008). In this experiment, the fractions of cells with different number of foci were quantitated. To compare our results with these measurements, we estimated the difference between levels of foci-containing nuclei in wild-type and ERCC1/XPFdefective cell cultures at 12,24 , and $48 \mathrm{~h}$ after irradiation. Since the experimental data (Ahmad et al. 2008) represents the separate assessment of foci kinetics in 


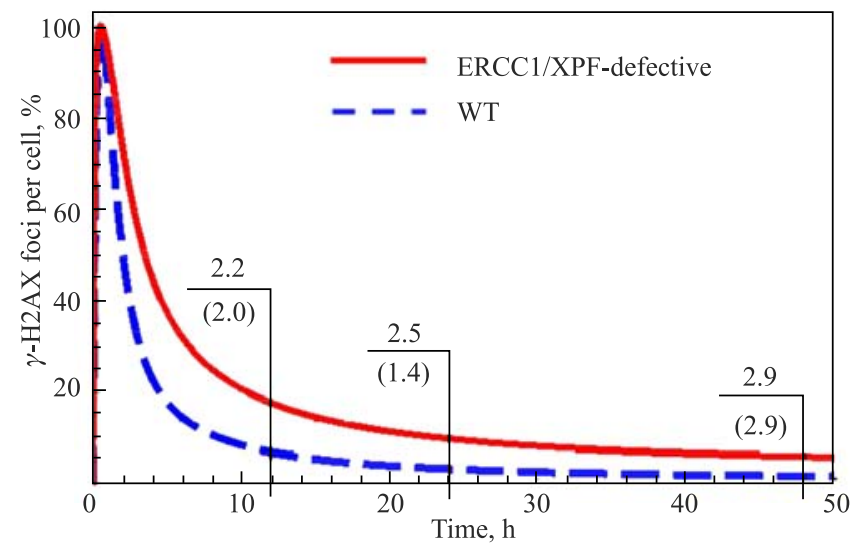

Fig. 11. Calculated time-courses of $\gamma-\mathrm{H} 2 \mathrm{AX}$ remaining in ERCC1/XPF-defective cells after exposure to $\gamma$-rays at the dose of $2 \mathrm{~Gy}$. The numbers without brackets represent the computed differences in foci levels at 12, 24, and $48 \mathrm{~h}$ postirradiation in ERCC1/XPFdeficient and wild-type (WT) cells; the numbers in brackets are the experimentally observed differences in percentage of cells containing more than two foci (Ahmad et al. 2008)

ERCC1- and XPF-deficient cells, we recalculated these results to obtain average levels of foci-containing cells defective in both functions. For the comparison we took the data on cells with more than two foci. In ERCC1/XPF-defective cells, the experimentally observed percentage of nuclei with more than two foci was 2.0-, 1.4-, and 2.9-times higher at 12,24 , and $48 \mathrm{~h}$ postirradiation than in wild-type cells. For these times our calculations gave the differences of 2.2-, 2.5-, and 2.9-times which are close to experimental data (Fig. 11).

\section{DISCUSSION}

The model approach proposed in our work is attempted to demonstrate a possible mechanistic description of three major repair systems capable to eliminate DNA DSBs in mammalian and human cells exposed to ionizing radiation. The mathematical description of these systems is carried out in compliance with the concepts of modern system biology and with the simulation methods of studying complicate biological networks. It reconstructs adequately the basic processes of the NHEJ, HR, and SSA networks. The developed models provide topological views of the NHEJ, HR, and SSA systems, which contributes to clarifying their biological relations. It shows possible connections between the biochemical processes of the repair pathways, some of which are still hardly accessible by real experiments. 
In our analysis, in addition to the most discussed repair mechanisms represented by NHEJ and HR, we also simulate SSA. Since this pathway is a recombinational one and requires similar mechanism of end resection as well, it is sometimes considered as an additional sub-pathway of HR (Sung and Klein 2006). Despite this similarity, recently published comprehensive reviews distinguish, however, SSA from HR, considering it as the third major DSB repair system (Heyer et al. 2010; Krejčl et al. 2012). Simultaneously we use a relatively abstract approach to describe the specific HR sub-pathways observed at its final stages. As these processes are still poorly assessed experimentally, mainly from the point of participating enzymes, we simply merge them into two pathways distinguished by the formation of $\mathrm{dHJ}$. Nevertheless, if the appropriate experimental data is obtained, the model can be extended to cover new findings. In our model we do not consider either the alternative end-joining (a-NHEJ), since there is a lack of an unambiguous phenomenological model for this process (Dueva and Iliakis 2013). Moreover, according to (Neal and Meek 2011) and (Dueva and Iliakis 2013), a-NHEJ exhibits slower kinetics, as well as HR and it is suppressed in the presence of $\mathrm{Ku}$. It means that in simulation of realistic experiment performed presumably with nonsynchronous cell cultures, the absence of this alternative pathway will not have any impact on the time-course of $\gamma$-H2AX foci in cells with normal function of $\mathrm{Ku}$. The influence of a-NHEJ can be appreciable only in cells defective in classical NHEJ, where it may result in the disturbance of slow component of the repair. In this case, the difference between the results of our simulation and experimental data can be observed.

In our model, the choice of the pathway is regulated by kinetics of particular repair processes. Since $\mathrm{Ku}$ and MRN can bind to the same DSBs (Neal and Meek 2011), and fast repair, if fails, can be changed to slow one (Shibata et al. 2011), it is impossible to differentiate between the fractions of lesions that follow exactly the NHEJ, HR, or SSA pathway. Therefore the most appropriate assumption concerning the pathway choice is to introduce the total number of DSBs initially induced by radiation and the part of irreparable damage, as it is done in our study.

Using our model we determined values for NHEJ, HR, and SSA rate constants which were the same for both low- and high-LET radiations, saving $K_{10}$ which depends on LET and repair status of cells. It contributes to flexibility of the proposed approach. Our calculated values, however, appear to be different from those obtained in other studies by at least two reasons. First, we consider the action of three systems together, while existing studies deal with individual repair pathways (Cucinotta et al. 2008; Taleei et al. 2012). Second, preceding models were developed mainly for sparsely ionizing radiations and did not attempt to find a set of parameters satisfying both low- and high-LET exposure.

In our work, the same reaction rate constants are applied to reconstruct DSB repair in several types of mammalian and human cells. In our opinion, it seems to 
be an adequate approximation at the moment, due to the absence of comprehensive data sets assessing kinetics of different repair stages in identical cell lines. In this regard, our approach reflects certain average rate of repair proceeding in a nonsynchronous culture. This interpretation meets most of realistic experiments when the number of radiation-induced foci is counted in cells, randomly taken from the exponentially grooving cultures exhibiting different repair rate due to diversity of cell cycle phase distribution.

With the purpose of estimating the initial yield of DSB, we use a relatively simple function approximating experimental data on number of lesions per Gy and per diploid genome. More accurate calculations can be done by combining our model with any track structure simulation technique providing the precise estimation of initial distribution of DNA lesions under exposure to corpuscular radiation. Doing this, our model can be modified to describe the repair of DSBs possessing different complexity.

We suggest that our approach is valid through the LET range of 0.2-236 $\mathrm{keV} / \mu \mathrm{m}$. In relation to radiation dose, our model possesses a different degree of validity for different repair stages. The kinetics of $\mathrm{Ku}$ recruitment is reconstructed well over the range of at least 1-137 Gy; time-courses of DNA-PKcs, RPA, Rad51, and $\gamma-\mathrm{H} 2 \mathrm{AX}$ foci induction are valid through, at least, $1 \mathrm{~Gy}, 1-4 \mathrm{~Gy}$, 1-10 Gy, and 1-2 Gy, respectively. The conclusion on the validity is based on the comparison of calculated results with the experimentally assessed kinetics of corresponding repair stages.

Finally, the proposed model summarizes a large number of experimental data on kinetics of DSB repair after the exposure to radiations with different LET. It allows the suggestion of new measurements to assess repair stages which are insufficiently studied experimentally to the date. According to our analysis, it mainly refers to the branching of HR at its late stages and to SSA in general.

\section{Appendix A \\ DETAILS OF THE NHEJ MODEL}

Equations of the NHEJ Model. The dynamical change in the levels of NHEJ intermediate complexes and $\gamma-\mathrm{H} 2 \mathrm{AX}$ foci is described by the following system of ordinary differential equations:

$$
\begin{aligned}
& \frac{d n_{0}}{d \tau}=\alpha(L) \frac{d D}{d t} N_{i r}-n_{0}\left(k_{1} x_{1}+p_{1} y_{1}\right)+k_{-1} x_{2}+p_{-1} y_{2} \\
& \frac{d x_{2}}{d \tau}=k_{1} N_{0} x_{1}-x_{2}\left(k_{-1}+k_{2} x_{3}\right)+k_{-2} x_{4}
\end{aligned}
$$




$$
\begin{aligned}
\frac{d x_{4}}{d \tau} & =k_{2} x_{2} x_{3}-x_{4}\left(k_{3}+k_{-2}\right) \\
\frac{d x_{5}}{d \tau} & =k_{3} x_{4}-k_{4} x_{5}^{2}+k_{-4} x_{6} \\
\frac{d x_{6}}{d \tau} & =k_{4} x_{5}^{2}-x_{6}\left(k_{-4}+k_{5} x_{7}\right)+k_{-5} x_{8} \\
\frac{d x_{8}}{d \tau} & =k_{-6} x_{10}+k_{5} x_{6} x_{7}-x_{8}\left(k_{-5}+k_{6} x_{9}\right) \\
\frac{d x_{10}}{d \tau} & =k_{-7} x_{12}+k_{6} x_{8} x_{9}-x_{10}\left(k_{-6}+k_{7} x_{11}\right) \\
\frac{d x_{12}}{d \tau} & =k_{7} x_{10} x_{11}-x_{12}\left(k_{8}+k_{-7}\right) \\
\frac{d x_{13}}{d \tau} & =k_{8} x_{12}+p_{10} y_{11}+p_{9} y_{12}+q_{6} z_{8} \\
\frac{d x_{14}}{d \tau} & =\frac{k_{9}\left(x_{5}+x_{6}+x_{8}+x_{10}+x_{12}\right) \cdot x_{15}}{k_{10}+x_{5}+x_{6}+x_{8}+x_{10}+x_{12}}-k_{11} x_{13}-k_{12} x_{14}
\end{aligned}
$$

Table A.1. Parameters of the model

\begin{tabular}{|l|l|l|l|}
\hline Parameter & \multicolumn{1}{|c|}{ Value } & Parameter & \multicolumn{1}{c|}{ Value } \\
\hline$a$ & 27.5 & $P_{2}$ & $9.20 \cdot 10^{-4} \min ^{-1}$ \\
$b$ & $2.43 \cdot 10^{-3}$ & $P_{3}$ & $2.00 \cdot 10^{3} \mathrm{M}^{-1} \min ^{-1}$ \\
$K_{1}$ & $1.67 \cdot 10^{-1} \mathrm{M}^{-1} \min ^{-1}$ & $P_{-3}$ & $1.47 \cdot 10^{-6} \min ^{-1}$ \\
$K_{-1}$ & $1.10 \cdot 10^{-2} \min ^{-1}$ & $P_{4}$ & $3.11 \cdot 10^{3} \mathrm{M}^{-1} \min ^{-1}$ \\
$K_{2}$ & $9.70 \cdot 10^{3} \mathrm{M}^{-1} \min ^{-1}$ & $P_{-4}$ & $2.58 \cdot 10^{-5} \min ^{-1}$ \\
$K_{-2}$ & $8.76 \cdot 10^{-3} \min ^{-1}$ & $P_{5}$ & $3.56 \cdot 10^{-1} \min ^{-1}$ \\
$K_{3}$ & $3.10 \cdot 10^{-2} \mathrm{M}^{-1} \min ^{-1}$ & $P_{6}$ & $2.00 \cdot 10^{2} \mathrm{M}^{-1} \min ^{-1}$ \\
$K_{4}$ & $2.30 \cdot 10^{4} \mathrm{M}^{-1} \min ^{-1}$ & $P_{-6}$ & $4.14 \cdot 10^{-6} \min ^{-1}$ \\
$K_{-4}$ & $6.44 \cdot 10^{-6} \min ^{-1}$ & $P_{7}$ & $8.86 \cdot 10^{3} \mathrm{M}^{-1} \min ^{-1}$ \\
$K_{5}$ & $2.54 \cdot 10^{-1} \mathrm{M}^{-1} \min ^{-1}$ & $P_{8}$ & $1.20 \cdot 10^{-4} \min ^{-1}$ \\
$K_{-5}$ & $1.38 \cdot 10^{-1} \min ^{-1}$ & $P_{9}$ & $1.01 \cdot 10^{-5} \min ^{-1}$ \\
$K_{6}$ & $3.01 \cdot 10^{-1} \mathrm{M}^{-1} \min ^{-1}$ & $P_{10}$ & $4.60 \cdot 10^{-3} \min ^{-1}$ \\
$K_{-6}$ & $2.21 \cdot 10^{-2} \min ^{-1}$ & $Q_{1}$ & $1.30 \cdot 10^{2} \mathrm{M}^{-1} \min ^{-1}$ \\
$K_{7}$ & $4.55 \cdot 10^{3} \mathrm{M}^{-1} \min ^{-1}$ & $Q_{-1}$ & $2.85 \cdot 10^{-6} \min ^{-1}$ \\
$K_{-7}$ & $5.34 \cdot 10^{-2} \min ^{-1}$ & $Q_{2}$ & $5.00 \cdot 10^{2} \mathrm{M}^{-1} \min ^{-1}$ \\
$K_{8}$ & $9.20 \cdot 10^{-3} \min ^{-1}$ & $Q_{3}$ & $1.00 \cdot 10^{2} \mathrm{M}^{-1} \min ^{-1}$ \\
$K_{9}$ & $2.77 \cdot 10^{-3} \min ^{-1}$ & $Q_{-3}$ & $1.01 \cdot 10^{-5} \min ^{-1}$ \\
$K_{10}$ & $1.93 \cdot 10^{-7} / N_{i r} \mathrm{M}$ & $Q_{4}$ & $2.76 \cdot 10^{-8} \min ^{-1}$ \\
$K_{11}$ & $1.25 \cdot 10^{-3} \min ^{-1}$ & $Q_{5}$ & $1.40 \cdot 10^{3} \mathrm{M}^{-1} \min ^{-1}$ \\
$K_{12}$ & $1.85 \cdot 10^{-1} \min ^{-1}$ & $Q_{-5}$ & $7.91 \cdot 10^{-6} \min ^{-1}$ \\
$P_{1}$ & $2.91 \cdot 10^{1} \mathrm{M}^{-1} \min ^{-1}$ & $Q_{6}$ & $1.93 \cdot 10^{-1} \min ^{-1}$ \\
$P_{-1}$ & $2.21 \cdot 10^{-6} \min ^{-1}$ & & \\
\hline
\end{tabular}


The initial conditions of this system for wild-type cells are the following: $n_{0}(0)=\alpha(L) D, x_{2}(0)=x_{4}(0)=x_{5}(0)=x_{6}(0)=x_{8}(0)=x_{10}(0)=x_{12}(0)=$ $x_{13}(0)=x_{14}(0)=0$. The values of variables $x_{1}, x_{3}, x_{7}, x_{9}, x_{11}$, and $x_{15}$ are set to be constant and equal to $x_{1}$.

In Eqs. (A.1), $n_{0}$ is the scaled number of radiation-induced DBSs; $N_{i r}$ is the nondimensional share of irreparable DSBs; $x_{1}, x_{3}, x_{7}, x_{9}$, and $x_{11}$ are scaled intracellular concentrations of the Ku, DNA-PKcs, LigIV/XRCC4/XLF, PNK, and Pol enzymes, respectively; $x_{2}, x_{4}, x_{5}, x_{6}, x_{8}, x_{10}, x_{12}$, and $x_{13}$, are normalized intracellular concentrations of intermediate complexes represented by $[\mathrm{DSB} \cdot \mathrm{Ku}], \quad[\mathrm{DSB} \cdot \mathrm{DNA}-\mathrm{PK} / \mathrm{Art}], \quad\left[\mathrm{DSB} \cdot \mathrm{DNA}-\mathrm{PK} / \mathrm{Art}^{\mathrm{P}}\right], \quad$ [Bridge, [Bridge $\cdot \operatorname{LigIV} / \mathrm{XRCC} 4 / \mathrm{XLF}], \quad[$ Bridge $\cdot \operatorname{LigIV} / \mathrm{XRCC} 4 / \mathrm{XLF} \cdot \mathrm{PNKP}$ ], [Bridge $\cdot \mathrm{LigIV} / \mathrm{XRCC} 4 / \mathrm{XLF} \cdot \mathrm{PNKP} \cdot \mathrm{Pol}]$, and [dsDNA]; $x_{14}$ is the scaled level of $\gamma$-H2AX foci; $x_{15}$ is the normalized level of histone variant H2AX; and $k_{i}$ are scaled rate constants. The variables of the model are normalized per $\mathrm{Ku}$ total cellular level: $n_{0}=N_{0} / X_{1}$ and $x_{i}=X_{i} / X_{1}$. In terms of molar concentration, this level was estimated as $X_{1}=N /\left(N_{A} V_{\text {nucl }}\right)=9.19 \cdot 10^{-7} \mathrm{M}$, where $N=400000$ is the number of Ku molecules per cell (Neal and Meek 2011), $N_{A}$

Table A.2. Values of the $N_{i r}$ parameter. The data is ordered by the values of LET

\begin{tabular}{|c|c|c|c|c|c|c|}
\hline \multirow{2}{*}{$N_{i r}$} & \multirow{2}{*}{$\begin{array}{l}\text { Type of } \\
\text { exposure }\end{array}$} & \multirow{2}{*}{$\begin{array}{c}\mathrm{LET}, \\
\mathrm{keV} / \mu \mathrm{m}\end{array}$} & \multicolumn{3}{|c|}{ Repair status } & \multirow{2}{*}{ Reference } \\
\hline & & & NHEJ & HR & SSA & \\
\hline 0.01 & $\gamma$-rays & $\sim 0.2$ & + & + & + & Asaithamby et al. 2008 \\
\hline 0.12 & $\gamma$-rays & $\sim 0.2$ & + & + & $\begin{array}{l}\text { ERCC1/ } \\
\mathrm{XPF}^{-}\end{array}$ & Ahmad et al. 2008 \\
\hline 0.01 & USX & $\sim 0.2$ & + & + & + & This work \\
\hline 0.43 & $\mathrm{X}$-rays & $\sim 0.2$ & $\begin{array}{l}\text { DNA- } \\
\text { PKcs - }\end{array}$ & + & + & Rothkamm et al. 2003 \\
\hline 0.2 & $\mathrm{X}$-rays & $\sim 0.2$ & LigIV - & + & + & Okayasu 2012 \\
\hline 0.33 & X-rays & $\sim 0.2$ & + & BRCA2 - & + & Shibata et al. 2011 \\
\hline 0.04 & ${ }^{16} \mathrm{O}, 1 \mathrm{GeV} / \mathrm{u}$ & 14 & + & + & + & Asaithamby et al. 2008 \\
\hline 0.08 & ${ }^{28} \mathrm{Si}, 1 \mathrm{GeV} / \mathrm{u}$ & 44 & + & + & + & Asaithamby et al. 2008 \\
\hline 0.1 & ${ }^{12} \mathrm{C}, 0.29 \mathrm{GeV} / \mathrm{u}$ & 70 & + & + & + & Okayasu 2012 \\
\hline 0.2 & ${ }^{12} \mathrm{C}, 0.29 \mathrm{GeV} / \mathrm{u}$ & 70 & LigIV - & + & + & Okayasu 2012 \\
\hline 0.3 & ${ }^{56} \mathrm{Fe}, 0.3 \mathrm{GeV} / \mathrm{u}$ & 150 & + & + & + & Asaithamby et al. 2008 \\
\hline 0.58 & $\begin{array}{c}{ }^{12} \mathrm{C}, 0.0098 \\
\mathrm{GeV} / \mathrm{u}\end{array}$ & 170 & + & + & + & Shibata et al. 2011 \\
\hline 0.86 & $\begin{array}{c}{ }^{12} \mathrm{C}, 0.0098 \\
\mathrm{GeV} / \mathrm{u}\end{array}$ & 170 & + & $\mathrm{BRCA} 2^{-}$ & + & Shibata et al. 2011 \\
\hline 0.09 & ${ }^{56} \mathrm{Fe}, 0.5 \mathrm{GeV} / \mathrm{u}$ & 200 & + & + & + & Okayasu 2012 \\
\hline 0.23 & ${ }^{56} \mathrm{Fe}, 0.5 \mathrm{GeV} / \mathrm{u}$ & 200 & LigIV - & + & + & Okayasu 2012 \\
\hline 0.4 & ${ }^{56} \mathrm{Fe}, 1 \mathrm{GeV} / \mathrm{u}$ & 236 & + & + & + & Asaithamby et al. 2008 \\
\hline
\end{tabular}


is the Avogadro constant, $V_{\text {nucl }}=7.23 \cdot 10^{-13} \mathrm{~L}$ is an average volume of the cell nucleus in human fibroblasts (Santos et al. 2013). In this consideration $x_{1}=1$.

Kinetic Parameters of NHEJ Model. The dimensionless parameters of Eqs. (A. 1) are $k_{1}=K_{1} X_{1} / K_{8}, k_{-1}=K_{-1} / K_{8}, k_{2}=K_{2} X_{1} / K_{8}, k_{-2}=K_{-2} / K_{8}, k_{3}=$ $K_{3} / K_{8}, k_{4}=K_{4} X_{1} / K_{8}, k_{-4}=K_{-4} / K_{8}, k_{5}=K_{5} X_{1} / K_{8}, k_{-5}=K_{-5} / K_{8}$, $k_{6}=K_{6} X_{1} / K_{8}, \quad k_{-6}=K_{-6} / K_{8}, \quad k_{7}=K_{7} X_{1} / K_{8}, \quad k_{-7}=$ $=K_{-7} / K_{8}, k_{8}=K_{8} / K_{8}=1, k_{9}=K_{9} / K_{8}, k_{10}=K_{10} / X_{1}, k_{11}=K_{11} / K_{8}$, and $k_{12}=K_{12} / K_{8} . K_{8}$ here is the rate of final NHEJ process resulting in the production of the repaired dsDNA and unwinding of all repair factors. The reason why we chose this constant as a scaling factor is the assumed independence of this parameter on possible variations due to the competition of repair pathways at earlier stages. This assumption can be important mainly for future modifications of the model, when rate constants of early stages are planned to connect with the damage complexity.

\section{Appendix B \\ DETAILS OF THE HR MODEL}

Equations of the HR Model. The kinetics of the HR intermediate complexes is described by the following system of ordinary differential equations:

$$
\begin{aligned}
\frac{d y_{2}}{d \tau} & =p_{1} n_{0} y_{1}-y_{2}\left(p_{2}+p_{-1}\right), \\
\frac{d y_{3}}{d \tau} & =p_{2} y_{2}-p_{3} y_{3} y_{4}+p_{-3} y_{5}, \\
\frac{d y_{5}}{d \tau} & =p_{3} y_{3} y_{4}-y_{5}\left(p_{-3}+p_{4} y_{6}+q_{1} z_{1}\right)+p_{-4} y_{7}+q_{-1} z_{2}, \\
\frac{d y_{7}}{d \tau} & =p_{4} y_{5} y_{6}-y_{7}\left(p_{5}+p_{-4}\right), \\
\frac{d y_{8}}{d \tau} & =p_{-6} y_{10}+p_{5} y_{7}-p_{6} y_{8} y_{9}, \\
\frac{d y_{10}}{d \tau} & =p_{6} y_{8} y_{9}-y_{10}\left(p_{7}+p_{-6}\right), \\
\frac{d y_{11}}{d \tau} & =p_{7} y_{10}-y_{11}\left(p_{8}+p_{10}\right), \\
\frac{d y_{12}}{d \tau} & =p_{8} y_{11}-p_{9} y_{12} .
\end{aligned}
$$

The initial conditions of this system for wild-type cells are the following: $y_{2}(0)=y_{3}(0)=y_{5}(0)=y_{7}(0)=y_{8}(0)=y_{10}(0)=y_{11}(0)=y_{12}(0)=0$. The values of $y_{1}, y_{4}, y_{6}$, and $y_{9}$ variables are set to be constant and equal to $x_{1}$. 
In Eqs.(B.1), $y_{1}, y_{4}$, and $y_{6}$ are scaled intracellular concentrations of the MRN, RPA, and Rad51/Rad51par/BRCA2 complexes, respectively; $y_{9}$ is the normalized level of incoming homologous sequence designated as $\left[\mathrm{DNA}_{\text {inc }}\right] ; y_{2}$, $y_{3}, y_{5}, y_{7}, y_{8}, y_{10}, y_{11}$, and $y_{12}$ are normalized intracellular concentrations of the [DSB $\cdot$ MRN/CtIP/ExoI/Dna2], [ssDNA], [ssDNA · RPA], [ssDNA $\cdot$ RPA $\times$ $\times \operatorname{Rad} 51 / \operatorname{Rad} 51$ par/BRCA2], [Rad51 filament], [Rad51 filament. DNA inc $_{\text {, }}$, [D-loop], and [dHJ] intermediate complexes, respectively; and $p_{i}$ are scaled rate constants. The variables are also normalized per the $\mathrm{Ku}$ total cellular level as $y_{i}=Y_{i} / X_{1}$.

Kinetic Parameters of HR Model. The scaled reaction rates in Eqs. (B. 1) are $p_{1}=P_{1} X_{1} / K_{8}, p_{-1}=P_{-1} / K_{8}, p_{2}=P_{2} / K_{8}, p_{3}=P_{3} X_{1} / K_{8}, p_{-3}=P_{-3} / K_{8}$, $p_{4}=P_{4} X_{1} / K_{8}, p_{-4}=P_{-4} / K_{8}, p_{5}=P_{5} / K_{8}, p_{6}=P_{6} X_{1} / K_{8}, p_{-6}=P_{-6} / K_{8}$, $p_{7}=P_{7} X_{1} / K_{8}, p_{8}=P_{8} / K_{8}, p_{9}=P_{9} / K_{8}$, and $p_{10}=P_{10} / K_{8}$. The same scaling factors $X_{1}$ and $K_{8}$ are chosen for parameter normalization.

\section{Appendix C \\ DETAILS OF SSA MODEL}

Equations of SSA Model. The dimensionless form of the equations for SSA model is represented as

$$
\begin{aligned}
& \frac{d z_{2}}{d \tau}=q_{1} y_{5} z_{1}-z_{2}\left(q_{-1}+q_{2} z_{2}\right) \\
& \frac{d z_{3}}{d \tau}=q_{2} z_{2}^{2}-q_{3} z_{3} z_{4}+q_{-3} z_{5} \\
& \frac{d z_{5}}{d \tau}=q_{3} z_{3} z_{4}-z_{5}\left(q_{4}+q_{-3}\right) \\
& \frac{d z_{6}}{d \tau}=q_{4} z_{5}-q_{5} z_{6} z_{7}+q_{-5} z_{8} \\
& \frac{d z_{8}}{d \tau}=q_{5} z_{6} z_{7}-z_{8}\left(q_{6}+q_{-5}\right)
\end{aligned}
$$

The initial conditions of this system for wild-type cells are the following: $z_{2}(0)=z_{3}(0)=z_{5}(0)=z_{6}(0)=z_{8}(0)=0$. The values of variables $z_{1}, z_{4}$, and $z_{7}$ are set to be constant and equal to $x_{1}$.

In Eqs. (C.1), $z_{1}, z_{4}$, and $z_{7}$ are scaled cellular levels of Rad52, ERCC1/XPF, and LigIII enzymes, respectively; $z_{2}, z_{3}, z_{5}, z_{6}$, and $z_{8}$ are scaled intracellular concentrations of the [ssDNA - RPA - Rad52], [Flap], [Flap - ERCC1/XPF], $\left[\mathrm{dsDNA}_{\text {nicks }}\right]$, and $\left[\mathrm{dsDNA}_{\text {nicks }} \cdot \mathrm{LigIII}\right]$ intermediate complexes, respectively; and $q_{i}$ are scaled rate constants. The variables are also normalized per $\mathrm{Ku}$ total cellular level as $z_{i}=Z_{i} / X_{1}$. 
Kinetic Parameters of SSA Model. The scaled reaction rates in Eqs. (C.1) are $q_{1}=Q_{1} X_{1} / K_{8}, q_{-1}=Q_{-1} / K_{8}, q_{2}=Q_{2} X_{1} / K_{8}, q_{3}=Q_{3} X_{1} / K_{8}, q_{-3}=$ $Q_{-3} / K_{8}, q_{4}=Q_{4} / K_{8}, q_{5}=Q_{5} X_{1} / K_{8}, q_{-5}=Q_{-5} / K_{8}$, and $q_{6}=Q_{6} / K_{8}$. In this case, the same factors $X_{1}$ and $K_{8}$ are used for scaling rate constants.

\section{Acknowledgements}

The authors gratefully acknowledge partial financial support provided by the JINR Grants No.14-091-01 and No.14-092-04 and the JINR-ARE Project No. 301"Mathematical Modelling of Genetic Regulatory Networks in Bacterial and Higher Eukaryotic Cells". The authors also thank JINR Laboratory of Informational Technologies for providing an access to the computing facilities. The authors acknowledge Ms. I. L. Avvakumova for suggestions to this paper.

\section{REFERENCES}

1. Ahmad A. et al. ERCC1-XPF endonuclease facilitates DNA double-strand break repair // Mol. Cell. Biol. 2008. V.28. P. 5082-5092. doi:10.1128/MCB.00293-08.

2. Anderson J.A. et al. Participation of DNA-PKcs in DSB repair after exposure to high- and low-LET radiation // Radiat. Res. 2010. V.174(2). P. 195-205. doi: 10.1667/RR2071.1.

3. Andres S.N. et al. Crystal structure of human XLF: a twist in nonhomologous DNA end-joining // Mol. Cell. 2007. V.28. P. 1093-1101. doi: 10.1016/j.molcel.2007.10.024.

4. Asaithamby A. et al. Repair of HZE-particle-induced DNA double-strand breaks in normal human fibroblasts // Radiat. Res. 2008. V.169(4). P.437-446. doi: 10.1667/RR1165.1.

5. Bastin M. et al. A mathematical model of homologous recombination in cultured cells // J. Theor. Biol. 1992. V. 156. P. 513-524.

6. Bertocci B. et al. Nonoverlapping functions of DNA polymerases mu, lambda, and terminal deoxynucleotidyltransferase during immunoglobulin $\mathrm{V}(\mathrm{D}) \mathrm{J}$ recombination in vivo // Immunity. 2006. V.25. P. 31-41. doi: 10.1016/j.immuni.2006.04.013.

7. Blier P. R. et al. Binding of Ku protein to DNA. Measurement of affinity for ends and demonstration of binding to nicks // J. Biol. Chem. 1993. V. 268(10). P. 7594-601.

8. Bryans M., Valenzano M. C., Stamato T. D. Absence of DNA ligase IV protein in XR-1 cells: evidence for stabilization by XRCC4 // Mutat. Res. 1999. V.433. P.53-58.

9. Buck D. et al. Cernunnos, a novel nonhomologous end-joining factor, is mutated in human immunodeficiency with microcephaly // Cell. 2006. V. 124. P. 287-299. doi: 10.1016/j.cell.2005.12.030.

10. Chen B. P. et al. Cell cycle dependence of DNA-dependent protein kinase phosphorylation in response to DNA double strand breaks // J. Biol. Chem. 2005. V. 280. P. 14709-14715.

11. Cucinotta F. A. et al. Kinetics of DSB rejoining and formation of simple chromosome exchange aberrations // Int. J. Radiat. Biol. 2000. V. 76. P. 1463-1474. 
12. Cucinotta F.A. et al. Biochemical kinetics model of DSB repair and induction of $\gamma$-H2AX foci by nonhomologous end joining // Rad. Res. 2008. V.169. P. 214-222. doi: 10.1667/RR1035.1/.

13. Dueva R., Iliakis G. Alternative pathways of nonhomologous end joining (NHEJ) in genomic instability and cancer // Transl. Cancer Res. 2013. V.2(3). P. 163-177. doi: 10.3978/j.issn.2218-676X.2013.05.02.

14. Frank K.M. Late embryonic lethality and impaired V(D)J recombination in mice lacking DNA ligase IV // Nature.1998. V.396. P. 173-177.

15. Frankenberg-Schwager M. Single-strand annealing, conservative homologous recombination, nonhomologous DNA end joining, and the cell cycle-dependent repair of DNA double-strand breaks induced by sparsely or densely ionizing radiation // Radiat. Res. 2009. V. 171(3). P. 265-73. doi: 10.1667/RR0784.1.

16. Goodhead D.T. Saturable repair models of radiation action in mammalian cells // Radiat. Res. 1985. V. 104 (Suppl.). P. 58-67.

17. Gottlich B. et al. Rejoining of DNA double-strand breaks in vitro by single-strand annealing // Eur. J. Biochem. 1998. V. 258(2). P. 387-95.

18. Grawunder U. et al. Activity of DNA ligase IV stimulated by complex formation with XRCC4 protein in mammalian cells // Nature. 1997. V.388. P. 492-495.

19. Gulston M. et al. Clustered DNA damage induced by $\gamma$ radiation in human fibroblasts (HF19), hamster (V 79-4) cells and plasmid DNA is revealed as Fpg and Nth sensitive sites // Nucl. Acids Res. 2002. V.30(15). P. 3464-3472. doi: 10.1093/nar/gkf467.

20. Hammarsten $O, C h u$ G. DNA-dependent protein kinase: DNA binding and activation in the absence of Ku // Proc. Natl. Acad. Sci. U. S. A. 1998. V.95. P. 525-530.

21. Harper J.V., Anderson J.A., O'Neill P. Radiation induced DNA DSBs: Contribution from stalled replication forks // DNA Repair. 2010. V.9. P.907-913. doi:10.1016/j.dnarep.2010.06.002.

22. Hefferin M.L., Tomkinson A.E. Mechanism of DNA double-strand break repair by nonhomologous end joining // DNA Repair. 2005. V. 4. P. 639-648.

23. Heyer W.-D., Ehmsen, K.T. Liu J. Regulation of Homologous Recombination in Eukaryotes // Annu. Rev. Genet. 2010. V.44. P. 113-139. doi: 10.1146/annurev-genet051710-150955.

24. Heyer W.D. et al. Rad54: the Swiss Army knife of homologous recombination // Nucl. Acids Res. 2006. V.34. P. 4115-4125. doi: 10.1093/nar/gkl481.

25. Hoglund E. et al. DNA damage induced by radiation of different linear energy transfer: initial fragmentation // Int. J. Radiat. Biol. 2000. V.76(4). P. 539-547. doi: $10.1080 / 095530000138556$

26. Huang X., Darzynkiewicz Z. DNA repair protocols. Mammalian systems, in: Henderson, D.S. (Ed.), Cytometric assessment of histone H2AX phosphorylation. A reporter of DNA damage // Humana Press. Inc., Totowa, 2006. P. 73-80.

27. Karimi-Busheri F. et al. Molecular characterization of a human DNA kinase // J. Biol. Chem. 1999. V.274(34). P. 24187-24194. 
28. Kiefer J. A repair fixation model based on classical enzyme kinetics, in: Kiefer, J. (Ed.), Quantitative Models in Radiation Biology. Springer-Verlag, Berlin, 1988. P. 171-180.

29. Koch C.A. et al. XRCC4 physically links DNA end processing by polynucleotide kinase to DNA ligation by DNA ligase IV // Embo J. 2004. V. 23(19). P. 3874-3885. doi: 10.1038/sj.emboj.7600375.

30. Krejči et al. Homologous recombination and its regulation // Nucl. Acids Res. 2012. V.40(13). P. 5795-5818. doi:10.1093/nar/gks270.

31. Kurosawa A., Adachi N. Functions and Regulation of Artemis: A Goddess in the Maintenance of Genome Integrity // J. Radiat. Res. 2010. V. 51(5). P. 503-509.

32. Lee J.H.; Paull T.T. Direct activation of the ATM protein kinase by the Mre11/Rad50/Nbs1 complex // Science. 2004. V.304(5667). P.93-96. doi: 10.1126/science.1091496.

33. Lobrich M. et al. Nonrandom distribution of DNA double-strand breaks induced by particle irradiation // Int. J. Radiat. Biol. 1996. V.70(5). P.493-503. doi: 10.1080/095530096144680.

34. Ma, Y. et al. A biochemically defined system for mammalian nonhomologous DNA end joining // Mol. Cell. 2004. V. 16. P. 701-713. doi:10.1016/j.molcel.2004.11.017

35. Ma, Y. et al. Hairpin opening and overhang processing by an Artemis/DNA-dependent protein kinase complex in nonhomologous end joining and $\mathrm{V}(\mathrm{D}) \mathrm{J}$ recombination // Cell. 2002. V. 108. P. 781-794.

36. MacPhail S.H., Olive P.L. RPA foci are associated with cell death after irradiation // Radiat. Res. 2001. V. 155(5). P. 672-679. doi: 10.1667/00337587(2001)155[0672:RFAAWC]2.0.CO;2.

37. Mah L.J., El-Osta A., Karagiannis T. C. cH2AX: a sensitive molecular marker of DNA damage and repair // Leukemia. 2010. V.24. P. 679-686. doi: 10.1038/leu.2010.6.

38. Mahaney B.L., Meek K., Lees-Miller S. P. Repair of ionizing radiation-induced DNA double-strand breaks by nonhomologous end joining // Biochem. J. 2009. V. 417. P. 639-650. doi: 10.1042/BJ20080413.

39. Mani R.S. et al. Dual modes of interaction between XRCC4 and polynucleotide kinase/phosphatase: implications for nonhomologous end joining // J. Biol. Chem. 2010. V.285. P.37619-37629. doi:10.1074/jbc.M109.058719.

40. Meek K. et al. Trans autophosphorylation at DNA-dependent protein kinase's two major autophosphorylation site clusters facilitates end processing but not end joining // Mol. Cell. Biol. 2007. V. 27. P. 3881-3890. doi: 10.1128/MCB.02366-06.

41. Moshous D. et al. Artemis, a novel DNA double-strand break repair/V(D)J recombination protein, is mutated in human severe combined immune deficiency // Cell. 2001. V. 105(2). P. 177-186.

42. Moshous D. et al. A new gene involved in DNA double-strand break repair and $\mathrm{V}(\mathrm{D}) \mathrm{J}$ recombination is located on human chromosome 10p // Hum. Mol. Genet. 2000. V.9(4). P. 583-588.

43. Motycka T.A. et al. Physical and functional interaction between the XPF/ERCC1 endonuclease and hRad52 // J. Biol. Chem. 2004. V. 279(14). P. 13634-13639. doi:10.1074/jbc.M313779200. 
44. Moynahan M.E., Jasin, M. Mitotic homologous recombination maintains genomic stability and suppresses tumorigenesis // Nat. Rev. Mol. Cell Biol. 2010. V.11. P. 196-207.

45. Neal J. A., Meek K. Choosing the right path: does DNA-PK help make the decision? // Mutat. Res. 2011. V.711(1-2). P. 73-86. doi: 10.1016/j.mrfmmm.2011.02.010.

46. Negritto M.C. Repairing Double-Strand DNA Breaks // Nature Education. 2010. V.3(9). P. 26.

47. O'Driscoll M. et al. DNA ligase IV mutations identified in patients exhibiting developmental delay and immunodeficiency // Mol. Cell. 2001. V. 8. P. 1175-1185.

48. Okayasu R. Repair of DNA damage induced by accelerated heavy ions - a minireview // Int. J. Cancer. 2012. V. 130. P.991-1000. doi: 10.1002/ijc.26445.

49. Pawelczak K.S., Turchi J.J. Purification and characterization of exonucleasefree Artemis: Implications for DNA-PK-dependent processing of DNA termini in NHEJ-catalyzed DSB repair // DNA Repair. 2010. V.9. P.670-677. doi: 10.1016/j.dnarep.2010.03.002.

50. Ramsden D. Polymerases in nonhomologous end joining: Building a bridge over broken chromosomes // Antioxid. Redox Signal. 2011. V. 14(12). P. 2509-2519. doi: 10.1089/ars.2010.3429.

51. Reynolds P. et al. The dynamics of Ku70/80 and DNA-PKes at DSBs induced by ionizing radiation is dependent on the complexity of damage // Nucl. Acids Res. 2012. V.40(21). P. 10821-10831. doi:10.1093/nar/gks879.

52. Rooney $S$. et al. Defective DNA repair and increased genomic instability in Artemisdeficient murine cells // J. Exp. Med. 2003. V. 197. P. 553-565.

53. Rothkamm K. et al. Pathways of DNA double-strand break repair during the mammalian cell cycle // Mol. Cell. Biol. 2003. V.23(16). P. 5706-5715. doi: 10.1128/MCB.23.16.5706-5715.2003.

54. Rydberg B. Clusters of DNA Damage Induced by Ionizing Radiation: Formation of Short DNA Fragments. II. Experimental Detection // Radiat. Res. 1996. V. 145(2). P. 200-209.

55. Saleh-Gohari N. et al. Spontaneous homologous recombination is induced by collapsed replication forks that are caused by endogenous DNA single-strand breaks // Mol. Cell. Biol. 2005. V. 25. P. 7158-7169. doi: 10.1128/MCB.25.16.7158-7169.2005.

56. Santos M. D. et al. Influence of the DNA density on the number of clustered damages created by protons of different energies // Nucl. Instrum. Meth. B. 2013. V. 298. P. 47-54. doi: 10.1016/j.nimb.2013.01.009.

57. Sargent R. G. et al. Role of the nucleotide excision repair gene ERCC1 in formation of recombination-dependent rearrangements in mammalian cells // Nucl. Acids Res. 2000. V.28(19). P. 3771-3778. doi: 10.1093/nar/28.19.3771.

58. Shibata A. et al. Factors determining DNA double-strand break repair pathway choice in G2 phase // EMBO J. 2011. V.30. P. 1079-1092. doi: 10.1038/emboj.2011.27.

59. Shrivastav M. et al. DNA-PKes and ATM co-regulate DNA double-strand break repair // DNA Repair. 2009. V. 8. P.920-929. doi:10.1016/j.dnarep.2009.05.006. 
60. Singleton M.R. et al. Structure of the single-strand annealing domain of human RAD52 protein // Proc. Nat. Acad. Sci. U.S. A. 2002. V.99(21). P. 13492-13497. doi: $10.1073 /$ pnas.212449899.

61. Sung P., Klein H. Mechanism of homologous recombination: mediators and helicases take on regulatory functions // Nat. Rev. Mol. Cell. Bio. 2006. V.7. P.739-750. doi: $10.1038 / \mathrm{nrm} 2008$.

62. Symington L.S. Role of RAD52 epistasis group genes in homologous recombination and double-strand break repair // Microbiol. Mol. Biol. Rev. 2002. V. 66(4). P. 630-70. doi: 10.1128/MMBR.66.4.630-670.2002.

63. Taleei $R$. et al. The nonhomologous end joining (NHEJ) mathematical model for the repair of double-strand breaks: II. Application to damage induced by ultrasoft X-rays and low-energy electrons // Rad. Res. 2013. V.179. P.540-548. doi: http://dx.doi.org/10.1667/RR3124.1/

64. Taleei R., Nikjoo H. The nonhomologous end joining (NHEJ) pathway for the repair of DNA double-strand breaks: I. A mathematical model // Rad. Res. 2013. V. 179. P. 530-539. doi: 10.1667/RR3123.1.

65. Taleei R., Weinfeld M., Nikjoo H. Single-strand annealing mathematical model for double-strand break repair // J. Mol. Eng. Syst. Biol. 2012. V.1. P.1-10. doi: 10.7243/2050-1412-1-1.

66. Van Dyck E. et al. Visualization of recombination intermediates produced by RAD52mediated single-strand annealing // EMBO Rep. 2001. V.2(10). P.905-909. doi: 10.1093/embo-reports/kve201.

67. Walker J.R., Corpina R.A., Goldberg J. Structure of the Ku heterodimer bound to DNA and its implications for double-strand break repair // Nature. 2001. V.412. P. 607-614.

68. Wallace S. S. Enzymatic processing of radiation-induced free radical damage in DNA // Radiat. Res. 1998. V. 150. P. 60-79.

69. Williams G.J., Lees-Miller S.P., Tainer J.A. Mre11-Rad50-Nbs1 Conformations and the control of sensing, signaling, and effector responses at DNA double-strand breaks // DNA Repair. 2010. V.9(12). P.1299-1306. doi: 10.1016/j.dnarep.2010.10.001.

70. Yaneva M., Kowalewski T., Lieber M.R. Interaction of DNA-dependent protein kinase with DNA and with Ku: biochemical and atomic-force microscopy studies // EMBO J. 1997. V. 16. P. 5098-5112.

71. Yoo S., Dynan W. S. Geometry of a complex formed by double-strand break repair proteins at a single DNA ends: requirement of DNA-PKcs induced inward translocation of Ku protein // Nucl. Acids Res. 1999. V.27. P. 4679-4686.

Received on May 8, 2014. 


\section{Редактор Э. В. Ивашкевич}

Подписано в печать 30.09.2014.

Формат $60 \times 90 / 16$. Бумага офсетная. Печать офсетная.

Усл. печ. л. 2,3. Уч.-изд. л. 3,3. Тираж 205 экз. Заказ № 58342.

Издательский отдел Объединенного института ядерных исследований 141980 , г. Дубна, Московская обл., ул. Жолио-Кюри, 6.

E-mail: publish@jinr.ru www.jinr.ru/publish/ 